\title{
LA OCASIÓN COMO ELEMENTO ESENCIAL DEL ACCIDENTE DE TRABAJO EN ITALIA Y SU ENFOQUE JURIDICO-LEGAL EN SUDAMÉRICA.
}

\author{
THE OCCASION AS AN ESSENTIAL ELEMENT OF ACCIDENT AT \\ WORK IN ITALY AND ITS LEGAL APPROACH IN SOUTH AMERICA
}

\author{
IRVING ALDO ROJAS VALENTINO* \\ Universidad de Milán, Italia
}

\begin{abstract}
Resumen: El presente artículo nos brinda un alcance mayor respecto a la ocasión como requisito fundamental en la definición y determinación del accidente de trabajo, su desarrollo histórico y su definición actual en Italia y en parte de Europa; partiendo de los parámetros dictados por la doctrina civilista, su concepción en los primeros años dentro del seguro social y su redefinición junto al mayor alcance que viene teniendo el riesgo profesional como objeto de la tutela del seguro en referencia. Así también se da una percepción de como el concepto de ocasión de trabajo viene siendo considerado en Sudamérica, tanto a nivel legislativo como jurisdiccional y su impacto en lo social.
\end{abstract}

Palabras claves: accidente de trabajo; causa; ocasión; seguro social; riesgo profesional.

\begin{abstract}
This article gives an overview about the occasion as a fundamental requirement for the definition and determination of the work accident, its historical development and current definition in Italy and part of Europe; starting from the parameters dictated by the doctrine of civil law, its conception in the first years within social security and its redefinition together with the greater scope of work-related risk as the object of the protection of the social insurance. There is also gives a perception of how the concept of work occasion, is being considered in South America, both at a legislative and judicial and its impact on social issues.
\end{abstract}

\footnotetext{
* Profesor contratado de la Universidad de Milán. Doctorando del PhD en Ciencias Jurídicas en la Sapienza Universidad de Roma, Magister en Derecho del Trabajo y Relaciones Industriales por la Universidad de Milán, con posgrado en Perfeccionamiento y Alta Especialización en Derecho Laboral por la Universidad de Milán. Con estudios de pregrado realizados en la Facultad de Derecho y Ciencias Políticas en la Universidad Nacional Mayor de San Marcos. Abogado. Email: irving.rojas@unimi.it
}

Este artículo fue recibido el 29 de abril de 2018 y aprobado el 11 de junio de 2018. 
Key words: accident at work; cause; occasion; social security; occupational hazard.

\section{Introducción}

La problemática de una adecuada definición de accidentes de trabajo, así como las correspondientes tutelas sanitarias y económicas que a partir de este evento se derivan, nos llevan a centrarnos en uno de los supuestos que aún no se encuentra clarificado del todo a nivel sudamericano, en su conceptualización y alcances, este es el caso de la ocasión como requisito elemental en la configuración del accidente de trabajo.

Debido al pragmatismo predominante, una interpretación histórica ligada a los conceptos tradicionales de la doctrina civilista, ha encuadrado el supuesto de la ocurrencia del accidente de trabajo, no bajo los preceptos propios del Derecho Laboral, sino más bien buscando otorgar cierta garantía proteccionista, tanto al empleador como a la actividad laboral propiamente dicha, en el entendido que fomentar la industria, a todo costo, es el único camino al desarrollo. Esta visión práctica ha hecho que en Sudamérica el alcance proteccionista de la ocasión de trabajo no haya logrado un mayor desarrollo.

Tanto la doctrina como la jurisprudencia sudamericana se han inclinado mayoritariamente a darle una misma connotación al supuesto de la ocasión de trabajo con la causalidad, en relación con la actividad laboral como causa objetiva y directa del accidente de trabajo, entendiendo de manera análoga ambos supuestos y llegando a concebir la idea que el trabajo no solo es fuente de riquezas sino también de accidentes. La causalidad ha sido por años el único supuesto imperante, tanto en el criterio de las entidades aseguradoras como a nivel jurisdiccional, es así que, en nuestros ordenamientos nos cuesta concebir la idea de alguna forma de accidente de trabajo que no esté directamente relacionada con el desarrollo de la actividad laboral propiamente dicha; es por ello que, por ejemplo, muchas legislaciones latinoamericanas, a fin de otorgar una mayor protección a la clase trabajadora, han empezado a incluir en sus ordenamientos nacionales al accidente in itinere como un tipo «especial» de accidente de trabajo, dejando de lado el supuesto ocasional que lo origina o, peor aún, hay legislaciones que directamente excluyen este tipo de accidentes, a pesar que dentro de su definición de accidente de trabajo se encuentra el supuesto de la ocasión.

No es poca la jurisprudencia en la región que ha sancionado de manera reiterativa la posibilidad de la existencia de accidentes de trabajo que no resulten indemnizables, menos aún resarcibles, esto porque resuelven en base a los principios que regulan la responsabilidad civil, en tanto, al no poder acreditar el incumplimiento del deber de seguridad del empleador, la conducta antijurídica o la culpabilidad, no acogen la pretensión del trabajador accidentado o, en un extremo mucho más radical, amparan la pretensión del trabajador señalando que el daño producido por el accidente de trabajo amerita una suposición del incumplimiento de las normas de prevención del empleador, subrogándose así en el lugar del legislador, buscando otorgar cierto nivel de protección a los trabajadores, creando precedentes vinculantes de obligatorio cumplimiento, pero sin ningún respaldo doctrinal o normativo, hecho que provoca inseguridad jurídica.

Ante esta situación tenemos que esclarecer el supuesto de la ocasión como parte integrante de la definición de accidente de trabajo, que lo encontramos literalmente presente en 
muchos de nuestros ordenamientos jurídicos sudamericanos y en otros tácitamente contenido en sus propias normas, señalando los lineamientos que motivaron su inclusión como un requisito esencial en la configuración del accidente de trabajo, en países en donde su alcance dimensional ha podido ya verse (y continua en constante evolución), al conseguir desplazar eficientemente a la relación causal entre trabajo y accidente, distanciando al concepto de ocasión, desde hace más de un siglo, de los criterios que regulan la responsabilidad civil, fundamentalmente gracias a la inclusión del seguro obligatorio contra accidentes de trabajo y enfermedades profesionales.

Debemos tener claro que, cuando hablamos de accidente de trabajo y de riesgo profesional, como (ahora sî) la causa que lo origina; a pesar de las medidas de protección que el empleador pueda aplicar durante las prestaciones laborales, siempre habrá un mínimo de probabilidad de la generación de un riesgo relacionado directa o indirectamente con la actividad laboral, que será generatriz de un accidente (nos referimos al riesgo y no al trabajo). Para ello se requiere también una tutela acorde a la naturaleza del infortunio, más aun para aquellos accidentes producidos dentro del supuesto de la ocasión de trabajo, cuya relación con la actividad laboral no es causal pero si teleológica, los cuales, para nuestras realidades, aún se encuentran en un limbo en relación con su encuadramiento profesional.

Es así que, en base a este supuesto, se podría llegar a establecer una tutela mucho más amplia y garantista contra los accidentes de trabajo, en favor del trabajador, incluso en los supuestos en los cuales el empleador llegue a acreditar el cumplimiento de sus obligaciones emanados del contrato de trabajo (normas de prevención, seguridad, etc.), estando a que, a pesar de cumplir con todas ellas, el trabajador siempre, de alguna forma, estará expuesto a algún tipo de riesgo que puede ser hasta genérico pero conexo, por la ocasión, con la prestación laboral que ejecuta.

\section{Evolución histórica de la ocasión de trabajo en Italia}

La dramática situación del trabajo que se presentó durante la década de 1870 y 1880 en Europa, debido principalmente al fenómeno de industrialización, llevó que sobre él se desarrolle, no solo a partir del enfoque de la clase política sino de una profundo análisis de la doctrina, una reflexión teórica en relación a la tradicional lectura de los principios que en tema de responsabilidad civil resultaban aplicables en dicho momento a los accidentes de trabajo ${ }^{1}$ que de manera exponencial iban en aumento a fines del siglo XIX.

El primer escollo por superar era la imposición normativa que en materia de responsabilidad civil establecían las legislaciones internas en Europa, que imponían, en su mayoría, al trabajador accidentado la insuperable y desgastante tarea de la carga de la prueba de la culpa del empleador en los accidentes de trabajo ${ }^{2}$. El principio del derecho romano «no hay

\footnotetext{
${ }^{1}$ Este conflicto de responsabilidades fue provocado por el desarrollo de las sociedades industriales. A mediados del siglo XIX parecía que las categorías del derecho civil eran insuficientes para abordar los problemas que traía consigo la industrialización. Se imponía el desarrollo de una legislación industrial propia y adecuada, que pudiera hacer frente a los principios que regulaban la responsabilidad civil; al respecto cfr. Ewald, François (1987). Assurance Sociale, en L'etat providence, Livro III. País: Bernand Grasset, pp.225 y ss.

${ }^{2}$ Para los ordenamientos jurídicos, codificados y no codificados del siglo XIX, el sistema de la responsabilidad civil se funda en estas reglas principales:

a) No puede haber responsabilidad si no se acredita la culpa o el dolo del sujeto agente (la culpa viene a ser considerada como un presupuesto necesario de la responsabilidad civil).
} 
responsabilidad sin culpa» resulta funcional a la lógica igualitaria de la sociedad burguesa y a la exigencia estática de los mercados de ese tiempo. Todo lo contrario, resulta profundamente inidónea su aplicabilidad al interno de la sociedad industrial, debido a la grave desigualdad presente en aquel momento.

Se buscó una tentativa de solución a dicha problemática, sentándose las bases en un debate que posibilitase la integración de los criterios de imputabilidad de la responsabilidad civil, pasando de una posición radical a una propuesta de efectuar, en el caso de los accidentes de trabajo, la inversión de la carga de la prueba y de la responsabilidad contractual; hecho que llevó a la doctrina civilista a denunciar, en voz alta, la intención de querer confundir la cuestión social con la jurídica (Fusinato, 1921: 27-39).

Luego se desarrolló la teoría del riesgo profesional, representando el primer tentativo de elaboración teórica de la responsabilidad objetiva por riesgo de empresa; su concepción no era «absoluta», tanto el caso fortuito como la fuerza mayor quedaban fuera de los límites de su aplicación, al ser determinado por factores externos que no se podían comparar con otros eventos que fueran predecibles por el empleador. Respecto a los accidentes imputables a la culpa del trabajador, la solución fue una propuesta parcial de inclusión al riesgo profesional, téngase en consideración que, para la época, muchos de los factores que llevaban a la negligencia del trabajador eran originados por las peligrosas condiciones en las cuales se trabajaba, haciendo aún más difícil la tarea de distinguir entre la culpa imputable al trabajador del riesgo inherente de la empresa (Ludovico, 2012: 7-20).

En Italia, el establecimiento de la ocasión como elemento esencial en el accidente de trabajo, surgió a partir del debate originado por la Ley $\mathrm{N}^{\circ} 80$, de fecha 17 de marzo de 1898, promulgada por el Rey Umberto I, que sancionaba en su artículo 7: «El seguro debe ser realizado a costo del empleador o dueño de la empresa, industria o constructora para todos los casos de muerte o lesiones personales proveniente de un accidente, que ocurra por causa violenta, en ocasión del trabajo y cuyas consecuencias tenga una duración mayor de cinco días (de reposo)».

El seguro obligatorio, a la que refiere la ley antes descrita, debe su construcción doctrinal a una suerte de compromiso social entre el empleador y los trabajadores. A los primeros, se les imponía el pago de una póliza, concediéndoles a cambio, la especial regla de la exoneración de la responsabilidad civil; mientras que, a los segundos, se les ofrecía la garantía de una atención inmediata, incluso en casos en que el evento no resultase imputable al empleador, hecho que llevaba a la correspondiente perdida del derecho al reintegro del resarcimiento del daño ${ }^{3}$. Si bien

b) El concepto de culpa sobre el cual se hace referencia identifica principalmente al comportamiento subjetivo caracterizado a partir de la negligencia, imprudencia, impericia, y a implicancias morales (el acto culposo viene a ser equiparable a un acto moralmente reprobable).

c) Las reglas de la responsabilidad civil, que disciplinan el acto ilícito culposo, asumen una función "sancionatoria" de la culpa (y cumplen, además, una función "intimidatoria" dirigida a prevenir eventuales comportamientos dañosos).

d) Las reglas de responsabilidad civil señalan que solo los actos que una persona realiza (voluntariamente, con intención o por negligencia) pueden resultar en una sanción en su contra. Es, en otras palabras, el principio que "cada uno actúa bajo su propio riesgo", que derivan de las normas codificadas en los ordenamientos de la Europa Continental y de las normas del common law. Aquellos que actúan bajo su propio riesgo son libres de actuar (pero deben asumir las consecuencias de sus acciones, si ellas causan a terceros daños por culpa). Para un mayor estudio al respecto cfr. Alpa, Guido y Mario Bessone (2001). La responsabilità civile. Milano: Giuffrè Editore, pp. 25 y ss.

3 Según la opinión tradicional, la comparación entre resarcimiento e indemnización debería ser hecha por individuales tipos de daño, debiendo distinguirse el daño «diferencial» del daño «complementario»; a la primera 
el seguro fue obligatorio e impuesta por ley, este quedaba condicionado al regular cumplimiento por parte del empleador, con el riesgo para el trabajador que, ante la falta del pago de la póliza correspondiente, este último quedará totalmente desprotegido (Mori, 1950: 466) (Hernández, 1972: 36) (Agnelli, 1902: 1008).

Posterior a ello, tanto a nivel jurisprudencial ${ }^{4}$ como doctrinario ${ }^{5}$ coexistió la noción que para la configuración del accidente de trabajo tendría que darse el supuesto que el trabajo se presentase como causa eficiente, directa o indirecta del accidente ${ }^{6}$.

Eran otros momentos, en los cuales los diversos ordenamientos europeos buscaban darle a la actividad laboral y al accidente de trabajo una relación causal, originada históricamente por la teoría de la responsabilidad civil del empleador, quien tenía entre otros deberes, la obligación de la seguridad del trabajador ${ }^{7}$, es así que emerge la expresión «deudor de seguridad» ${ }^{8}$; ya en esa época se había podido observar que la obligación de empleador de vigilar el cumplimiento de las normas de seguridad por parte de sus trabajadores resultaba insuficiente, como fue también el caso de la legislación uruguaya de $1914^{9}$, por lo que se buscó darle otro sentido más justo, a partir de la relación ocasional entre accidente y trabajo.

categoría deberían pertenecer los tipos de daño incluidos por el seguro obligatorio, por las cuales la eventual diferencia respecto a las prestaciones sociales podrían ser resarcidas nomas en caso de superarse la regla de la exoneración. Al contrario, el daño complementario debería ser reconducido a los tipos de daños que están fuera de la seguridad social y que como tales serían resarcibles según las reglas de la responsabilidad civil; para un mayor estudio cfr. Ludovico, Giuseppe (2017). «Origen y evolución del seguro obligatorio de accidente de trabajo y enfermedades profesionales en Italia». Revista chilena de derecho del trabajo y de la seguridad social, 8 (15): 13-36. Disponible en goo.gl/FxFyb8.

${ }^{4}$ La Corte de Milano sostenía que el trabajo tendría que constituía la causa directa del accidente, al respecto cfr. Sentencia de fecha 18 de noviembre de 1901, en Foro italiano, 1992, I, 1402; mientras que la Corte de Casación de Firenze, restringían la producción del accidente a la ocasión del trabajo, cfr. Sentencias de fecha 18 de enero de 1904, en Temi, 1904, 93 y 96.

${ }^{5} \mathrm{Al}$ respecto Pateri señala que «el accidente es resarcible en cuanto sea por causa eficiente, directa o indirecta del trabajo», citado por Carnelutti, Francesco (1913). Infortuni sul lavoro, I. Roma: Athenaeum, p. 213.

${ }^{6}$ Asimismo, por su parte, el legislador francés formuló la Ley de fecha 9 de abril de 1898, que en su artículo 1 expone respecto de los «accidents survenus par le fait du travail ou à l'occasion du travail». Lo que resulta relevante para el análisis aquí son los «accident survenu par le fait du travail», en el entendido que son los accidentes que tienen por causa directa el trabajo; mientras corresponde a la denominación «accident à l'occasion du travail» a todos aquellos accidentes que no entran en el supuesto en el cual el trabajo no es causa directa, sino solo causa ocasional. Evidentemente la hipótesis de «accident survenu par le fait du travail», entendida en este modo, es lógicamente errada; o en el mejor de los casos inútil, por el hecho simple que el fait du travail, es una supuesto limitado, el cual se encuentra dentro de la occasion du travail, que tienen un alcance mucho más amplio. Al respecto Cfr. Carnelutti, Francesco (1913). Infortuni sul lavoro, I. Roma: Athenaeum, p. 216-217.

${ }^{7}$ El fundamento mayor de la obligación de seguridad se halla en el derecho del trabajador a la vida e integridad física, merecedor de la más elevada tutela; al respecto cfr. Igartua Miró, María Teresa (2015). Sistema de prevención de riesgos laborales. $3^{\circ}$ Ed. Madrid: Editorial Tecnos, p.136-137.

${ }^{8}$ Al respecto cfr. Pic, Paul (1903). Traité élémentaire de législation industrielle: Les lois ouvrières. Paris: A Rousseau, p. 752.

${ }^{9}$ A este propósito debemos de citar que en Uruguay, la Ley $\mathrm{N}^{\circ} 5032$ del 21 de julio de 1914, en su artículo 50, se había limitado a establecer la responsabilidad del empleador derivados de su deber de vigilar que todo trabajador de él dependiente cumpla con las medidas de resguardo y seguridad imprescindibles para la protección del personal en el centro de trabajo; evidentemente este simple sistema representativo de la responsabilidad patronal era insuficiente, se necesitaba sobre todo "prevenir" el accidente. En este sentido, entre 1915 y 1935 el Poder Ejecutivo emanó una serie de decretos dirigidos a imponer el uso de los medios de prevención que deberían de ser adaptados a las diversas áreas de la actividad industrial, así fue que se emitió la Ley $\mathrm{N}^{\circ} 10004$ del 28 de febrero de 1941, que en su artículo 1 
Volviendo a la legislación italiana antes descrita, para la ocurrencia del accidente laboral, este debe producirse en «ocasión» del trabajo. Ocasión no es causa -nos señala la doctrina- o al menos no es causa eficiente. La terminación de la antítesis filosófica y común de la causa eficiente es la causa ocasional ${ }^{10}$. Exigir que el trabajo sea causa directa o eficiente del accidente, es una posición abiertamente contraria a lo dictado por la referida ley, argumento que se condena por sí solo. Es más, no solo es contraria a la disposición legislativa, sino a la entidad lógica de la relación, que puede hallarse en medio del trabajo y del accidente. A partir de la génesis del accidente, el trabajo asume una función de causa ocasional (ocasión), no de causa eficiente (causa); que asuma esta última posición, no es tanto porque la ley no quiere, sino que no puede. Por lo demás, basta solo un poco de sentido común, sin siquiera realizar un mayor análisis, el trabajo no es por sí solo, un actor o un generador de accidentes, ni prepara el escenario para que baste un solo hecho extraño que determine la manifestación de un accidente, tiene que ocurrir siempre la intromisión de un elemento diverso, perturbador del normal desarrollo del trabajo ${ }^{11}$ para que el accidente suceda, y en este elemento diferente o en esta serie de elementos diferentes está la real causa eficiente del accidente, que es la lesión por causa violenta (Carnelutti, 1913: 214-216).

Es así como, si el evento ocasional es aquel que provoca la ocurrencia de un efecto, es decir que pone en condición una determinada causa para la producción de un determinado efecto, tal evento ocasional frente al accidente será el trabajo, esto claro, cada vez que el trabajo sea el hecho que determina la producción del accidente. Si la producción del accidente resulta de la combinación de dos elementos: el evento capaz de producir la lesión violenta y la persona del trabajador capaz de recibir esa lesión, aún se podrá decir que el trabajo es la causa ocasional (ocasión) del accidente, toda vez que este determina la combinación de esos dos elementos. Dicho en otras palabras, es el trabajo que determina la exposición del trabajador a la acción de dicho evento ocasional. Asimismo, la exposición del trabajador a la acción de los eventos capaces de producir en él lesiones, se denomina más adecuadamente «riesgo profesional».

Es así como el concepto emerge con más claridad, por lo que corresponde decir que el trabajo otorga la ocasión al accidente, es decir que el accidente que ocurre en ocasión de trabajo sucede siempre que el trabajo determina el riesgo del cual fue consecuencia el accidente. Es así como de un simple análisis lógico del argumento legislativo de la Ley $\mathrm{N}^{\circ} 80$ de 1898 que se ha

estableció: "Todo patrono es responsable civilmente de los accidentes que ocurran a sus obreros a causa del trabajo o en ocasión del mismo", además de establecer el deber del empleador de asegurar al trabajador contra accidentes de trabajo en el Banco de Seguros del Estado.

${ }^{10}$ Carnelutti señala que la causa eficiente y la causa ocasional son pensadas como concurrentes a la producción de un (mismo) efecto, la causa ocasional pertenece a la categoría de las concausas: no es toda la causa (de un efecto), es solo una parte de ella. ¿Pero qué parte? -Se pregunta Carnelutti- Aquí importa dirigirse al significado de las palabras y recordar también que la causa de la ocasión es la causa de la manifestación exterior de un efecto, el hecho por el cual un efecto potencial se convierte en real. Por ejemplo, para obtener un disparo es necesario tener algo de pólvora y una chispa, la causa ocasional del disparo es solo la chispa, porque determinar la realización del disparo. La ocasión seria entonces la concausa última, o la condición que completa el núcleo de las circunstancias agentes como causa (eficiente) del evento. Al respecto cfr. Carnelutti, Francesco (1913). Infortuni sul lavoro, I. Roma: Athenaeum: 218 y 219.

11 Téngase en cuenta el caso típico de un operario, que hace uso de una maquinaria, la cual el engranaje le cercena una mano o un brazo, aquí también, para que el accidente ocurra debe interponerse un factor extraño, atípico o anormal, que desvía el curso regular del trabajo, puede ser la desatención del operario, algún defecto de la maquinaria, la culpa o el dolo de terceros. 
podido concluir perfectamente en el concepto primigenio del denominado riesgo profesional; si este es el riesgo, que se manifiesta como consecuencia del trabajo, se concluye también que, frente al accidente que del riesgo deriva, el trabajo no puede asumir posición distinta que no sea la de la ocasión (Carnelutti, 1913: 223).

Por ello, cuando se dice que el trabajo determina el riesgo, se entiende que el trabajo debe asumir frente al riesgo una real y propia función de causalidad. Por su parte, es propio del concepto de ocasión que el evento ocasionante sea la causa de la producción del evento ocasionado, en este sentido precisamente se habla de causa ocasional. En la relación recíproca entre el trabajo y el riesgo, se puede hablar con certeza de este como un efecto y de aquel como una causa; mientras, lógicamente, no se puede decir lo mismo entre la relación del trabajo con el accidente. Considérese también la causa como el conjunto de condiciones a partir de las cuales deriva el efecto, no existe dificultad lógica en afirmar que, a partir de la ejecución del trabajo, se deriven una serie de riesgos determinados (riesgos profesionales); mientras que se tendría mucha dificultad, por las razones expuestas, para repetir la misma afirmación colocando al accidente en el lugar del riesgo. El riesgo, es decir la exposición al evento dañoso, deriva directamente del trabajo, sin la participación de otros hechos, no es así en el caso del accidente, porque este es generado sobre todo por un quid (evento capaz de producir la lesión corporal violenta), que con el trabajo no tiene nada que ver. Así, el vínculo que puede darse entre el trabajo y el accidente es constituido por el propio riesgo el cual, generado directamente por el trabajo, hace posible la aparición de aquel quid como causa eficiente del accidente (Carnelutti, 1913: 227).

La supuesta necesidad de establecer una directa relación causal entre el trabajo y el riesgo condujo a una precisa clasificación de los riesgos ${ }^{12}$ que atestiguaban la naturaleza profesional del evento, admitiéndose solo a la tutela, los accidentes provocados por un riesgo específico directo o propio, o a partir de un riesgo intrínseco al desarrollo de la prestación laboral, o de un riesgo especifico impropio o genérico agravado, es decir a partir de un riesgo que, aunque privado de una específica connotación profesional, fuese agravado por el cumplimiento de las obligaciones laborales. A falta de una relación de derivación causal con el trabajo, la aplicación de la tutela de del seguro era excluida para los eventos provocados por un riesgo genérico, entendiéndose como tal al riesgo que perjudica indistintamente a cualquier sujeto, sea este trabajador o un simple ciudadano (Ludovico, 2014: 135).

El riesgo asegurado es un elemento esencial en la estructura del seguro obligatorio, tanto porque es un requisito propio de la función aseguradora, como un requisito, ocurrido el evento, del derecho a las prestaciones correspondientes al accidente de trabajo. La noción de riesgo es dada a partir de la posibilidad, no del evento ${ }^{13}$ (Santoro Passarelli, 1948: 181).

La existencia del riesgo, entendida como posibilidad de la ocurrencia de un evento dañoso, condiciona la existencia y la permanencia del vínculo con el seguro, siendo tal existencia necesaria para tal efecto. No se puede decir lo mismo del evento cuya ocurrencia aparece, obviamente, necesaria solo para los efectos del derecho a las prestaciones. Desde la óptica de la determinación del accidente de trabajo, es preciso notar que el riesgo asegurado no se identifica

\footnotetext{
${ }^{12}$ Para un mayor análisis al respecto del riesgo y su clasificación, consúltese Barassi, Ludovico (1954). Previdenza Sociale e Lavoro Subordinato. Milano: Giuffrè Editore, p. 257-296.

${ }^{13}$ Por razones propias del presente estudio, corresponde descartar toda posibilidad de relacionar al riesgo con un evento futuro e incierto, como en tal sentido expone la definición Barassi, Ludovico (1954). Previdenza Sociale e Lavoro Subordinato. Milano: Giuffrè Editore: 257.
} 
con el riesgo profesional normal y típico de las distintas actividades, en donde esto pueda entenderse en modo tal de excluir los actitudes voluntarias (una especie de culpa grave) de los sujetos en la relación laboral, en el sentido que dichas actitudes alterarían o modificarían la estructura del propio riesgo profesional y por ello mismo se lograría excluirlos del seguro obligatorio.

En realidad la definición y el desarrollo del concepto de riesgo asegurado, que deriva de la exposición de la citada Ley $\mathrm{N}^{\circ} 80$ de 1898, no se limita al riesgo profesional, entendido en el sentido antes expuesto, en cuanto no se limita al solo riesgo del accidente inevitablemente relacionado con el ejercicio de la actividad laboral, sino comprende, en el concepto desarrollado por el legislador italiano, a los componentes causales de tal riesgo, componentes de tipo fortuito y componentes relacionados al comportamiento de los mismos sujetos partícipes del seguro (Alibrandi, 2002: 193).

Es sobre la noción de evento protegido que corresponde fijar ahora la atención para poder individualizar, más allá de la construcción del concepto de riesgo profesional, el fundamento teórico de la tutela del seguro; muy a menudo descuidada en su valor teórico, la noción de accidente de trabajo expresa un principio de tutela destinado a ascender a lo más alto del ordenamiento y que, en su momento, fue también conducido a los esquemas de la responsabilidad objetiva.

En mérito de aquella noción, reproducida en la legislación italiana en el artículo 2 del Texto único de las disposiciones para el seguro obligatorio contra los accidentes de trabajo y las enfermedades profesionales, Decreto de la Presidencia de la República $N^{\circ} 1124$ del $1965^{14}$, la tutela del seguro contra accidentes de trabajo encuentra su aplicación, ante la producción de cualquier evento ocurrido por causa violenta y «en ocasión del trabajo», siempre que se hayan producido efectos perjudiciales para la salud del trabajador (daño). Un sistema idéntico al anterior (el expuesto en la Ley $\mathrm{N}^{\circ} 80$ de 1898) que, diverso a la responsabilidad civil, no distingue entre los factores causales del evento, reconociendo un particular realce, en comparación con otras aseguraciones, a los componentes etiológicos del caso fortuito, de la fuerza mayor, del accionar de terceros, de la conducta dolosa o culposa del empleador y de aquella culposa del trabajador.

Esta noción delimita así, un concepto de riesgo que va más allá los límites de la responsabilidad objetiva, en la medida que no está más interesado en la gravedad del riesgo que, de otro lado, se constituiría en el criterio de imputación. Por tanto, el concepto de riesgo al que se refiere el legislador no está vinculado a la mayor probabilidad de la ocurrencia del evento determinado por la actividad laboral, sino al mayor riesgo de accidente que se cierne sobre el trabajador en la ejecución de sus prestaciones, teniendo la misma trascendencia cualquier evento que ocurra en «ocasión de trabajo». Es esta relación de ocasión con el trabajo la que permite configurar la profesionalidad del evento y define unilateralmente el concepto, prescindiendo de la imputabilidad, la que es en todo caso requisito necesario de la antijuridicidad.

\footnotetext{
${ }^{14}$ La norma refiere a los expuesto en el artículo 2 del Texto único de las disposiciones para el seguro obligatorio contra los accidentes de trabajo y las enfermedades profesionales, Decreto de la Presidencia de la República $\mathrm{N}^{\circ} 1124$ del 1965, publicado en el suplemento ordinario de la Gazzetta Ufficiale $\mathrm{N}^{\circ} 257$, el 13 de octubre de 1965 , que señala: «El seguro incluye todos los casos de accidentes ocurridos debido a causas violentas durante trabajo, del cual se ha derivado la muerte o la incapacidad permanente para trabajar, absoluta o parcial, o una discapacidad temporal absoluta que llevaría a la abstención del trabajo por más de tres días...».
} 
A partir de esta noción, la jurisprudencia italiana estuvo en grado de aplicar la tutela del seguro obligatorio a cualquier evento generado por un riesgo, incluso genérico, siempre que esté relacionado con el trabajo o con actividades meramente instrumentales ligadas a la ejecución de este, lo que demuestra que la ocasión de trabajo permite identificar el origen profesional del evento del que depende la aplicación de la tutela.

El riesgo profesional, una vez transformado en «riesgo social» ${ }^{15}$, perdió su connotación como criterio de imputabilidad del hecho antijurídico, superando así el mismo concepto de la imputabilidad y la naturaleza bilateral de la responsabilidad civil (contractual y extracontractual). Es a partir de este momento en el que se registra históricamente en Italia, el inicio de la Seguridad Social para los accidentes de trabajo y enfermedades profesionales, haciendo que el ordenamiento evolucione hacia un novedoso concepto de tutela. Es esta noción unitaria del evento lo que refleja uno de los «aspectos fundamentales y más típicos» de la tutela del seguro obligatorio, expresada en su característica función de seguridad social, distinguiéndose también así, de otro tipo de aseguraciones ligadas a la cobertura de la responsabilidad civil (Ludovico, 2012: 49-51).

Como hemos expuesto, ya para entonces era necesario que el evento haya ocurrido no a causa sino en ocasión del desarrollo de la actividad laboral y además de haberse producido en un determinado tiempo y lugar, que expusieran al trabajador al inminente riesgo que produjo el accidente, el cual posiblemente no hubiera ocurrido si el trabajador no hubiera realizado dicha actividad. ${ }^{16}$ En ocasión del desarrollo de la actividad laboral, como debe ser entendida de manera literalmente la frase «ocasión de trabajo», es decir, no en la ejecución propia, efectiva y normal de las actividades al trabajador encomendada por la empresa, sino basta una simple conexión con cualquiera de estas actividades. Debiéndose de excluir, a partir de esta interpretación extensiva del concepto, a las actividades que, si bien se podrían ejecutar en el mismo centro de trabajo, son totalmente extrañas y ajenas a cualquier actividad ordinaria que realiza el trabajador (Barassi, 1954: 316-317).

En este momento, para la configuración de un accidente producido con ocasión del trabajo no era suficiente que entre el accidente y el trabajo subsistiera una simple relación cronológica y topográfica, sino que era necesario que el trabajo haya determinado el riesgo, al cual el

\footnotetext{
${ }^{15}$ La metamorfosis de la vieja política de previsión en una política de prevención. La previsión, hasta ese entonces era una virtud individual por excelencia, se convierte en una virtud social y, como tal, sensible a lo que estaba pasando desde hace mucho como una paradoja, una contradictio in terminis, de la obligación. El seguro se vuelve obligatorio: las personas están aseguradas, pero eso también significa asegurarse de que estén aseguradas. Transformándola en un riesgo social, la inseguridad de cada uno se convierte en una problemática social. Si la necesidad sigue siendo un asunto individual, la carga de esa necesidad, el peligro que ella representa, es ahora un asunto social. Las causas de la inseguridad, los accidentes, las enfermedades y la vejez tienen un costo social que la sociedad, que ahora tiene el deber de asegurar, debe controlar y, si es posible, disminuir. Al respecto cfr. Ewald, François (1987). Assurance Sociale, en L'etat providence, Livro III. País: Bernand Grasset, p. 334.

${ }^{16}$ Según las referencias dadas en Italia, por el Instituto nacional para el seguro contra accidentes de trabajo y enfermedades profesionales (INAIL), ya para el año 1948 y solo en el sector industrial, las causas más frecuentes de accidentes de trabajo fueron las siguientes; en un rango de 100 accidentes no mortales: 27.92 eran debido al uso de maquinarias industriales, 21.75 a caídas del personal, 12.28 a manipulación de objetos pesados, 12.22 al uso de aparatos de transporte, 9.33 al uso de herramientas, 6.19 a materiales nocivos, 5.34 a caída de objetos pesados, 3.61 a motores y dínamos, $0.03 \mathrm{al}$ ambiente de trabajo, 3.41 a causas diversas; en un rango de 100 accidentes mortales: 25.75 a caídas del personal, 25.75 al uso de aparatos de transporte, 14.48 a caída de objetos pesados, 13.12 a materiales nocivos, 7.35 a manipulación de objetos pesados, 4.78 al uso de maquinarias industriales, 0.86 al uso de herramientas, 0.78 al ambiente de trabajo. Al respecto cfr. Pezzoli, Liberato (1953). «Associazioni sindacali e prevenzione infortuni». En Rivista italiana di previdenza sociale: 429.
} 
accidentado ha estado expuesto al sufrir el evento dañoso, haciendo que esta nueva fórmula de interpretación, ${ }^{17}$ evidentemente, acrecentase más el número de los accidentes de trabajo que resultasen indemnizables.

Durante la década de 1970, algunos conceptos respecto a la tutela del seguro obligatorio contra los accidentes de trabajo se redefinían, como consecuencia de lo dispuesto en el texto único antes descrito, en lo que concierne a la ocasión del trabajo, se señaló como un requisito que caracteriza la profesionalidad del evento ${ }^{18}$. Tal característica presupone al mismo tiempo una garantía y un límite respecto al ámbito de la aplicabilidad del seguro obligatorio; garantía y limites que le son inherentes a la misma función del citado seguro contra los accidentes de trabajo, dirigida a brindar al trabajador una tutela diferenciada de aquellos riesgos específicos a los cuales son expuestos debido al normal desenvolvimiento de la actividad productiva.

El enfoque que se le dio a la ocasión del trabajo, en este entonces, supuso un análisis del determinismo del accidente de trabajo, ya se tenía como un principio adquirido, tanto a nivel de la jurisprudencia y de la doctrina italiana que, en su génesis, para estos tipos de accidentes no solo intervenía el factor «trabajo» en función de la ocasión, sino que concurrían junto a él, otros numerosos posibles componentes causales. Tales componentes no se identificaban directamente con la causa ocasional, pudiendo ser diversos y de discreta relevancia para los efectos legales, en la medida en la cual intervinieron en su posición frente a la decisión legislativa. Y si fuera verdad que, en la hipótesis, uno o más de estos componentes causales fuesen excluidos de la ley, la causa ocasional, aunque permanezca igual en su definición típica, tendría un alcance normativo diferente.

Este enfoque de unificación de criterios resulta trascedente, tanto porque evidencia que los componentes causales del evento no se identifican directamente con la causa ocasional y porque demuestra como el análisis de la causa ocasional no se agota, definitivamente, con la solución legislativa de establecer el origen del accidente. La determinación del accidente se constituye a partir de la acción de la causa ocasional, la cual se actualiza dentro de los límites de la ocasión de trabajo y también, por esta vía, se profesionalizó a los componentes causales del evento reconocido por el legislador.

Tales componentes causales fueron, según la normativa italiana de aquel entonces, no solo el caso fortuito, la fuerza mayor, la acción de un tercero, sino que también la culpa del trabajador, así como la culpa y el dolo del empleador. Estos supuestos, que podrían ser los causantes de cualquier riesgo asegurado, no incidían por si solos en la clasificación profesional del accidente de trabajo, su clasificación tuvo que darse entonces, como se dijo anteriormente, a partir de la ocasión.

Es aquí donde se empezó apreciar la necesidad de efectuar una distinción conceptual, hasta ese momento no advertida, entre la ocasión y estos componentes causales reconocidos por la ley, los cuales, como se indicó, no incidían en la calificación profesional del evento,

\footnotetext{
${ }^{17}$ Así, el Tribunal de L'Aquila, en fecha 1 de febrero de 1948, hace la distinción, en atención al derecho a la indemnización por accidentes de trabajo, que este debe ser reconocidos no solo en el caso obvio de una relación de causalidad entre el trabajo y el accidente mismo, sino también cuando entre el trabajo y el accidente exista una relación ocasional; al respecto cfr. Rivista italiana di previdenza sociale, 1948, 486.

${ }^{18}$ Es la ocasión del trabajo que condiciona, de manera típica, el carácter profesional del evento, en cuanto concierne a su particular etiología; es a razón de tal singular etiología que, los accidentes de trabajo y, en mayor medida, las enfermedades ocupacionales asumen la cualidad específica y característica de la profesionalidad, al respecto cfr. Alibrandi, Giuseppe (2002). Infortunio sul lavoro e malattie profesionali, $11^{\circ}$ Ed. Milano: Giuffrè Editore, p. 321.
} 
reflejándose si sobre el riesgo asegurado, en cuando condicionan la posibilidad de la ocurrencia del accidente, ampliándola o reduciéndola. Es por esto que forman parte integral de la noción jurídica del riesgo y, desde luego, del evento como consecuencia de dicho riesgo. Naturalmente, otros supuestos causantes del evento, que no fueron reconocidos por la normativa italiana, no entraron en la noción jurídica de riesgo asegurado y, en consecuencia, tampoco se les otorga la correspondiente tutela. Desde el punto de vista jurídico formal es como si el evento no hubiese ocurrido, nótese que, no subsistiendo la tutela en razón a la causa del evento, no fue posible calificar a este como un accidente de trabajo, así sea que, por supuesto teórico, subsistiese la ocasión de trabajo (Alibrandi, 2002: 322-325).

\section{Enfoque actual de ocasión de trabajo en Italia}

Cuando hablamos de la ocasión del trabajo en la doctrina italiana, nos estamos refiriendo a uno de los requisitos elementales para la configuración del accidente de trabajo, no debemos entenderla ni confundirla con una mera condición causal, como se ha visto precedentemente, sino enfocarla desde la finalidad laborante ${ }^{19}$ por la cual se produjo el evento. Hacia esta última perspectiva se vienen orientando, ya desde varias décadas, mucho de los ordenamientos jurídicos que en materia de seguridad y salud en el trabajo, se han venido desarrollando en países económicamente más desarrollados ${ }^{20}$.

Por ello, la comprensión lexical de la palabra ocasión ${ }^{21}$ nos lleva a pensar inmediatamente en el motivo por el cual algo sucede, en la circunstancia o conjunto de circunstancias que hacen

\footnotetext{
${ }^{19}$ Es importante señalar que la doctrina alemana, en la década de 1920, ya se había expuesto la relación de finalidad entre el trabajo y el accidente; así se señala que el accidente debe de ocurrirle al trabajador no "mientras" sino "porque" trabaja, que fue en el enfoque doctrinal que se dio para la determinación del riesgo profesional. Para tal fin cfr. Schulz, Georg (1928). Abgrenzung zwischen Unfallversicherung und Krankenversicherung. Berlín, p. 14.

${ }^{20}$ Con idéntica terminología o de significado análogo, en un contexto definitivo más o menos amplio y comprensivo se ha venido usando en diversos ordenamientos jurídicos como: el numeral 1) del artículo 156 de la Ley general de la seguridad social española, Real Decreto Legislativo 8/2015, de 30 de octubre que señala: "Se entiende por accidente de trabajo toda lesión corporal que el trabajador sufra con ocasión o por consecuencia del trabajo que ejecute por cuenta ajena". El artículo L411-1 del Code de sécurité sociale francés señala que es considerado accidente de trabajo, cualquiera que sea la causa, el accidente ocurrido por el hecho o en ocasión del trabajo a cualquier personal asalariada o laborante, bajo cualquier modalidad o en cualquier lugar, para uno o más empleados. El artículo 7 de la Loi sur les accidents du travail belga del 10 de abril de 1971, señala que es considerado como accidente en el trabajo a todo accidente que sufra un trabajador en el curso y por el hecho de la ejecución del contrato de trabajo y que produzca una lesión. También se considera como accidente de trabajo, el accidente sufrido por el trabajador fuera del curso de la ejecución del contrato de trabajo, pero que es causado por un tercero como resultado de la ejecución de dicho contrato. El accidente ocurrió durante la ejecución del contrato de trabajo, se presume como accidente de trabajo, hasta que se demuestre lo contrario, debido al hecho de la ejecución de dicho contrato. Para la Social Security Act ingles de 1988, entra en el supuesto para otorgar el beneficio de incapacidad por lesiones industriales a cualquier evento involuntario o accidente de trabajo que ha producido una lesión personal a causa o en el curso de la actividad laboral; y en la guía del Department for Work and Pensions (DWP) se explica que un accidente viene a ser considerado en ocasión de trabajo, cuando ocurre porque el trabajador está ejecutando cualquier actividad a la que está obligado por el contrato de trabajo, o porque sus prestaciones implican un particular riesgo, o en actividades de rescate; sin embargo, si el trabajador realiza cualquier actividad a propia iniciativa, contras las directivas empresariales, es considerado accidente en ocasión del trabajo, si tiene como finalidad la propia producción y es ejecutado en el ámbito de sus prestaciones laborales.

${ }^{21}$ Cfr. Diccionario de la Real Academia de la Lengua Español, v. Ocasión:

Del lat. occasio, -ōnis.
} 
posible la ocurrencia de un evento; estas circunstancias que favorecen la producción de un evento pueden incluso no constituir la causa verdadera y necesaria para su configuración, ni ser siquiera, de manera independiente, suficientemente capaz como para poder desencadenarlo (De Matteis, 2011: 181).

Tampoco podemos pensar en haber logrado determinar su definición, desde una óptica simplista, cuando nos encontramos frente a la existencia de una relación entre el tiempo y/o lugar de la prestación laboral con el accidente mismo, porque podrían intervenir otros factores o circunstancias totalmente ajenas al ambiente de trabajo, a las maquinarias utilizadas o incluso a los propios trabajadores o terceros sujetos a la protección legal contra este tipo de eventos, que podrían conllevar a que no se configure el supuesto y por ende no se aplique la tutela correspondiente al evento (Corsalini, 2009: 9).

Así, para que un accidente sea considerado de trabajo, a partir del supuesto ocasional, puede originarse incluso a partir de situaciones imprevistas o extraordinarias, de la participación de terceros o por la culpa del mismo accidentado, pero siempre debe ser (no causado, pero sî) «ocasionado» por el trabajo, en el sentido que debe de preexistir una conexión no meramente marginal entre el accidente y la actividad laboral. La pura y simple correlación de tiempo y de lugar con el evento y la prestación laboral, no es por sí solo suficiente para la ocurrencia de la ocasión de trabajo, cuando intervienen factores o actividades del todo independientes del ambiente, de las maquinas o del trabajo, que constituyen las condiciones objetivas para la tutela ${ }^{22}$.

La trasformación de la realidad industrial, junto al desarrollo jurisprudencial y doctrinal, como se ha expuesto, y sobre todo el establecimiento del seguro obligatorio contra accidentes de trabajo que fue la respuesta del legislador italiano frente al alto índice de siniestralidad y la exigencia social de dar cobertura a una problemática que involucraba a todos los ciudadanos y no solo a los trabajadores; así fue que la definición de accidente de trabajo empezó a ser concebido más como un factor de necesidad social que requería una atención inmediata que, un evento generador de responsabilidad, manteniendo este último una relevancia meramente eventual que no se condiciona para nada con la intervención asistencial que requiere el accidente, el cual permanece ligada directamente al evento «ocasionado» por el trabajo, independientemente de su calificación como un hecho antijurídico. Es por este motivo que no se puede dividir la tesis que expone en el seguro obligatorio contra accidentes de trabajo, el desarrollo más coherente y puro del principio de riesgo profesional.

Lo antes expuesto ha llevado a demostrar las evidentes limitaciones de la lectura tradicional; así, la mismísima jurisprudencia italiana ha comenzado a preferir, en el lugar de la acostumbrada exposición carneluttiana, una lectura mucho más amplia de la noción de riesgo profesional $^{23}$, a la cual pueda reconducirse cada vez que un evento se produzca en ocasión de la prestación laboral.

(1) Oportunidad que se ofrece para ejecutar o conseguir algo.

(2) Causa o motivo por qué se hace o acaece algo.

${ }^{22}$ Así, la Corte Constitucional Italiana se pronuncia en la Sentencia de fecha 27 de julio de 1989, n. 462, en Rivista infortuni e malattie professionali, 1989, II, 81 y ss.

${ }^{23}$ El riesgo profesional no fue concebido como una responsabilidad «absoluta» ya que la noción de «caso fortuito o fuerza mayor» asumía la función de delimitar los confines de riesgo de la empresa, quedando así excluidos los eventos «extraños» a la empresa porque, determinados a partir de factores «externos», no eran comprables con los eventos que pudiera prevenir el empleador, cfr. Ludovico, Giuseppe (2012). Tutela previdenziale per gli infortuni sul lavoro e le malattie professionali e responsabilità civile del datore di lavoro. Milano: Giuffè Editore: 20. 
Del debate doctrinal y legislativo surgió el seguro obligatorio, como el momento culminante de un fatigoso proceso de reforma al cual se arribó, con la participación de sectores claramente opuestos. Por un lado, la fuerte resistencia dogmática a cualquier intervención en la responsabilidad civil y por el otro, la apremiante exigencia social de apresurar un remedio general y automático contra los accidente de trabajo; con un efecto innovador y, de alguna manera, sin considerar la radical superación que se dio de los mismos confines de la antijuridicidad y de la responsabilidad civil.

La construcción teórica del riesgo profesional constituyó una respuesta consecuencial a una apremiante exigencia de carácter doctrinal. De hecho, la explicación de la tutela del seguro obligatorio resulta muy apropiada, en tanto no se limitó a exponer una definición del accidente de trabajo que solo buscase prescindir de la imputabilidad que podría tener en el ámbito civilista, sino que buscó establecer el simple requisito de nexo ocasional con el trabajo (Ludovico, 2012: 51-52).

Es así que, según esta perspectiva, incluso los accidentes imputables a un riesgo impropio, no intrínsecamente relacionados con el desarrollo de las prestaciones típicas del trabajo, sino a una actividad preparatoria o instrumental al desenvolvimiento de las referidas prestaciones y conexos al cumplimiento de las exigencias laborales, deben también entenderse como ocurridos en ocasión del trabajo, incluso si están determinados por simples riesgos genéricos no provocados o agravados por las condiciones de trabajo.

Por ello, la noción de riesgo profesional viene a ser directamente identificada ahora en la relación de instrumentalidad con la actividad laboral, en el sentido que, distinto a la orientación tradicional, la tendencia actualmente mayoritaria deduce el origen profesional del evento, a partir de la simple conexión de finalidad subsistente con la actividad laboral y que en razón de la «falta de libertad» que deriva de la obligación del trabajador de adecuar su propia conducta dentro de los horarios de la prestación. ${ }^{24}$ Deriva de ello, con una clara posición distinta al enfoque tradicional, que la mera coincidencia con la actividad laboral es por si sola suficiente para justificar la indemnización del evento, salvo que la presencia en el centro de labores sea debida a circunstancias no reconducibles al desarrollo de las prestaciones ${ }^{25}$.

Se puede decir que el enfoque históricamente precedente, centrado en la naturaleza específica y agravada del riesgo y, asimismo, en la relación causal entre este último y la actividad laboral, ha sido sustituido por un criterio más acorde a la realidad industrial contemporánea, que se establece a partir del nexo de instrumentalidad entre la conducta originaria del evento y la actividad laboral. La noción de riesgo asegurado tiende así sustancialmente a coincidir, de un lado, con el comportamiento contractualmente obligado del trabajador y, del otro, con el deber de seguridad que recae sobre el empleador, ${ }^{26}$ el cual debe ejecutarlo, ejerciendo su poder de organización y dirección dentro de la empresa (Vallebona, 2015: 280).

\footnotetext{
${ }^{24} \mathrm{Al}$ respecto cfr. De Matteis, Aldo (1996). L'assicurazione obbligatoria contro gli infortuni sul lavoro e le malattie professionali. Torino: Utet, p. 33 y ss.

${ }^{25}$ En ese sentido, la jurisprudencia italiana en la sentencia de Casación de fecha 9 de agosto de 2003, n. 12035, ha declarado como no indemnizable por falta de conexión con las prestaciones laborales, el accidente ocurrido a una trabajadora que, saliendo de la agencia bancaria ubicada al interno del establecimiento de la fábrica, se resbaló, produciéndose una fractura.

${ }^{26}$ Para un mayor estudio cfr. De Matteis, Aldo (1996). L'assicurazione obbligatoria contro gli infortuni sul lavoro e le malattie professionali. Torino: Utet, p. 94; Del Punta, Riccardo (2017). «Tutela de la persona sul lavoro». En Diritto di Lavoro. $9^{\circ}$ Ed. Milano: Giuffrè Editore: 579-598.
} 
Es así como, gracias a esta amplia lectura de la noción de la ocasión de trabajo, que la tutela del seguro obligatorio ha ayudado a establecer en Italia y en países de economías más avanzadas, la posibilidad de ampliar la definición de accidentes de trabajo a otro tipo de eventos, que en un primer periodo no fueron considerados como tales, dándoles en la actualidad una configuración más idónea con estos tiempos y permitiéndoles obtener una cobertura indemnizatoria y también resarcitoria, según corresponda al evento acaecido, en relación al daño sufrido. Al respecto, solo por citar algunos ejemplos de eventos que por la ampliación del concepto se encuentra configurados actualmente como accidentes de trabajo, entre ellos tenemos: los accidentes provocados por actos criminales, de terceros, por la conducta culposa de los colegas u ocurridos durante las peleas entre trabajadores, en el trascurrir de los descansos, en los desplazamientos al interno de los ambientes de trabajo o en el accidente in itinere. (Ludovico, 2014: 139-142).

\section{El riesgo electivo}

La definición de riesgo electivo nace a partir de la hipótesis por la cual el trabajador crea voluntariamente un riesgo que no tiene ninguna relación con el desarrollo de sus actividades laborales y que, a veces, llega a estar en oposición a ellas y a las disposiciones que las reglamentan. En este caso el evento dañoso no puede ser considerado indemnizable, porque es la expresión, no de un riesgo profesional asegurado, sino de aquel riesgo electivamente provocado por el propio trabajador (Alibrandi, 1971: 453).

Para la doctrina es evidente que no subiste el derecho a la indemnización para los casos en los cuales el accidente derivó de un riesgo electo del trabajador, es decir cuando este sea consecuencia de un riesgo relacionado a un comportamiento voluntario, dirigido a satisfacer exigencias meramente personales y por ello, ajenas a las actividades laborales; es decir, es el riesgo generado a partir de una actividad que no tiene relación alguna con el desarrollo de la prestación o que aparece en modo irracional fuera de los límites de esta. Así sea que el evento lesivo haya ocurrido durante la jornada de trabajo y/o en el centro de labores, pero, evidentemente, careciera del nexo ocasional entre la actividad laboral y el accidente; cuando se esté frente a este supuesto estaremos hablando de un caso de riesgo por elección. ${ }^{27}$

Asimismo, con mucha frecuencia se comete error de considerar «riesgo electivo»a cualquier otro simple riesgo asumido por el trabajador. Si esta sería la interpretación correcta, cada uno de los accidentes derivados de un riesgo que el trabajador habría podido evitar deberían ser excluidos de cualquier tipo de seguro contra accidentes de trabajo, quedando al mismo tiempo sin ningún tipo de indemnización tantos accidentes derivados de la culpa o de la voluntad trasgresora de las normas de seguridad (por ejemplo, asumir el riesgo de quien no usa los implementos de seguridad, quien durante el trabajo se distrae pensando en otra cosa, o quien por premura, no usa las protecciones de las maquinarias que usa). En realidad, el riesgo electivo es un riesgo distinto, en el sentido de ser un riesgo totalmente extraño a la actividad laboral, la cual es materia de protección.

\footnotetext{
${ }^{27} \mathrm{Al}$ respecto cfr. Ferrari, Genaro e Giulia Ferrari (2004). Infortunio sul lavoro e le malattie professionali. Padova: Cedam, p. 172; Nicolini, Giovanni (1966). «Rischio elettivo ed infortunio indennizzabile». En Rivista di diritto del lavoro, I, 359; Pessi, Roberto (2006). Lezioni di diritto della previdenza sociale, Cedam, Padova: 413.
} 
Sin embargo, debe de agregarse que cuando el accidente ocurre a partir de una conexión, aunque sea mínima o aparente con las prestaciones laborales, el problema del riesgo electivo no se presenta. Por su parte, es un reto determinar la existencia del riesgo electivo cuando el accidente aparece, de alguna manera, a primera vista, relacionada con el trabajo realizado, porque, por ejemplo, ocurrido el accidente durante la jornada de trabajo o en el centro de labores o provocado por las herramientas o maquinaras de trabajo, se presentan como situaciones aparentemente laborales, por lo que para argumentar el riesgo electivo se necesita una investigación que, debe ser particularmente cuidadosa y exhaustiva, y una rigurosa demostración de la independencia de la conducta del trabajador con la esfera de la organización y con la finalidad prestacional del trabajo; y con ello, la extrañeza del riesgo enfrentado a aquellos riesgos propios de la modalidad y del requerimiento del trabajo desarrollado. Naturalmente, para la existencia del riesgo electivo no se debe presuponer que el comportamiento ejecutado por trabajador sea culposo; la culpa involucra el modo en el cual se exterioriza una actividad que, en el caso del riesgo electivo, no resulta asegurable (Corsalini, 2009: 18-19).

Delicada es la distinción que corresponde hacer en la práctica, para establecerse cuando se está frente a accidente de trabajo por culpa o por dolo del trabajador, y cuando frente a uno provocado a partir de un riesgo electivo, aun cuando este concepto está ya bien definido en la doctrina y la jurisprudencia italiana ${ }^{28}$ como lo hemos expuesto anteriormente, el cual define al riesgo electivo como una desviación puramente arbitraria de las normales conductas y formas en la ejecución de las prestaciones laborales, debido a una finalidad personal del trabajador, que implican riesgos diversos de aquellos inherentes a la normal modalidad de ejecución de la prestación. ${ }^{29}$ Según una posición más radical, reformula la definición antes descrita, señalando que el riesgo electivo está constituido por un supuesto idóneo, capaz de interrumpir cualquier conexión con la ocasión de trabajo y de privar del evento de cada aspecto de la profesionalidad. ${ }^{30}$ Los criterios jurisprudenciales italianos más recientes se han inclinado por configurar al riesgo electivo como el único límite excluyente de la ocasión del trabajo ${ }^{31}$.

La inclusión de una expresión que hace referencia al concepto de riesgo electivo para señalar los límites de aquel distinto (riesgo profesional), referido a la ocasión del trabajo, es particularmente significativa debido a la cercanía entre ambas nociones. Con una formula ya

\footnotetext{
${ }^{28}$ Es importante señalar que el riesgo electivo constituye un supuesto derivado de la jurisprudencia italiana que, no encontrado una respuesta explícita en su correspondiente ordenamiento normativo, encuentra sin embargo un claro fundamento en la indefectible relación causal e instrumental que debe de subsistir entre el riesgo del evento y la actividad laboral. Al respecto cfr. Giubboni, Stefano, Giuseppe Ludovico y Andea Rossi (2014). Infortuni sul lavoro e malattie professionali. Padiva: Cedam: 144.

${ }^{29}$ En ese sentido se pronunció la jurisprudencia italiana en Casación de fecha 18 de agosto de 1977, n.3789, en Rivista infortuni e malattie professionali, 1979, II, 630; Casación de fecha 3 de febrero de 1995, n. 1269, en Notiziario di giurisprudenza del lavoro, 1995, 464; Casación de fecha 3 de mayo de 1995, n. 6088; Casación de fecha 1 de septiembre de 1997, n. 8269; Casación de fecha 4 de diciembre de 2001, n. 15312.

${ }^{30}$ De este modo se pronunció el Tribunal Supremo Italiano en la Casación de fecha 6 de marzo de 1996, n. 1750, en Rivista infortuni e malattie professionali, 1996, II, 55.

${ }^{31}$ Así ha sido establecido en reiteradas sentencias italianas: Casación de fecha 19 de abril de 1999, n. 3885; Casación de fecha 2 de junio de 1999, n. 5419; Casación de fecha 9 de octubre de 2000, n. 13447; Casación de fecha 8 de marzo de 2001, n. 3363, en Giustizia civile, 2001, I, 2105 y Foro italiano, 2001, I, 1531; Casación de fecha 9 de enero de 2002, n. 190, en Giustizia civile, 2002, II, 328; en Giustizia civile, 2001, I, 2105; Casación de fecha de 13 de abril de 2002, n. 5354; Casación de fecha de 22 de abril de 2002, n. 5841; Casación de fecha de 3 de agosto de 2005, n. 16282.
} 
consolidada, el riesgo electivo puede ser individuado a través del concurso simultáneo de los siguientes elementos característicos: no debe ser solo un acto voluntario (esto en contraposición muchas veces a los actos de automaticidad del trabajo, que a menudo son causante de los accidentes), sino, más que todo, arbitrario, en el sentido de ilógico y extraño a la finalidad laborante; debe estar dirigido a satisfacer impulsos meramente personales (que permiten excluir las iniciativas, aunque incongruentes, pero motivadas a partir de la finalidad de la ejecución de la prestación laboral); debe afrontarse un riesgo diverso a los cuales estaría sujeto (por el riesgo profesional), así el evento tenga algún nexo derivado del desarrollo de la actividad laboral. En la determinación de la culpa, el dolo o el riesgo electivo, respectivamente, se debe tener presente la experiencia laboral del trabajador accidentado (De Matteis, 2011: 201-202).

\section{La culpa y el dolo del trabajador}

Para la doctrina, la conducta dolosa del trabajador no entra en el supuesto de riesgo asegurable, toda vez que tanto el empleador como el ente asegurador no están obligados a responder por los siniestros ocasionados por la conducta dolosa del trabajador. El dolo debe ser entendido como el diseño criminoso, deliberadamente asumido por parte del sujeto interesado en engañar a terceros, quien está en grado de producir un evento dañoso y de fingir la causa eficiente de este evento. Este accionar desbarata cualquier conexión etiológica entre el trabajo y el accidente, sin embargo la coloca como causa exclusiva de este último; así cuando el accidente «doloso» ocurra por causa violenta y como ocasión del trabajo, no puede ser definido propiamente como un «accidente» ${ }^{32}$, es decir fue un infortunio, una desgracia, una desventura, una fatalidad, en cuanto este hecho ha sido querido, buscado, provocado, perseguido por el trabajador; por otra parte, en comparación con el accidente ocurrido por riesgo electivo, este si es un accidente propiamente dicho, en el cual no se encuentra presente la ocasión de trabajo.

El accidente «doloso» ocurre como resultado de la acción u omisión del trabajador, quien ha previsto y querido que el evento suceda, a partir de su propio comportamiento. En la práctica se presenta en la forma de la autolesión ${ }^{33}$, simulación del accidente o del agravamiento doloso de una lesión personal a partir de un accidente, situaciones que no son referidas a los comportamientos que conlleva la mera conciencia y voluntad del hecho material, el denominado «dolo genérico» (por ejemplo: remover voluntariamente las medidas de seguridad de los equipos o maquinarias), sino más bien al «dolo específico», caracterizado por la voluntad de querer conseguir un fin particular ${ }^{34}$.

A este punto, la problemática radica en calificar el comportamiento voluntario pero contraria a la técnica operativa (dolo genérico), que incrementa el riesgo del accidente, pero sin

\footnotetext{
${ }^{32}$ Cfr. Diccionario de la Real Academia de la Lengua Español, v. Accidente:

(1) Suceso eventual que altera el orden regular de las cosas.

(2) Suceso eventual o acción de que resulta daño involuntario para las personas o las cosas.

${ }^{33}$ Sobre este argumento cfr. Baldi, Guido Maria (1930). «Cronache e storie della simulazione. Appunti e noterelle ai margini del proceso di Roma». En Rassegna della previdenza social, X, 7; Miraldi, Giovanni (1929). «Autolesionismo e simulazione nel campo degli infortuni sul lavoro: L'azione della Cassa nazionale infortuni». En Rassegna della previdenza social, I, 34; Giudici, Italo (1924). «Un caso di truffa in materia di assicurazione contro gli infortuni sul lavoro». En Rassegna della previdenza social. III. 25.

${ }^{34}$ Sobre la distinción entre dolo genérico y dolo especifico véase: Mantovani, Ferrando (1992). Diritto penale. Padiva: Cedam, p. 330; Antolisei, Francesco (1960). Manuale di diritto penale. Milano: Giuffrè Editore, p. 259.
} 
una finalidad ulterior que no sea la de eliminar de obstáculos y agilizar el trabajo, como en el caso de la eliminación de las medidas de seguridad. Este supuesto ha estado redirigido a la inobservancia voluntaria de las normas técnicas del uso de las maquinarias, la que ha sido llevada no por el dolo sino por la culpa grave ${ }^{35}$; asociándose también a la problemática del deber de control a cargo del empleador. No siempre emerge la responsabilidad individual del trabajador accidentado en la remoción de las medidas de seguridad, puede ser que dicha acción de remoción corresponda a otro autor, haciendo difícil individualizarse, ya sea el caso que suceda o no suceda el accidente, porque normalmente se trata de situaciones prolongadas en el tiempo. Al respecto la jurisprudencia italiana se ha pronunciado en el sentido de la responsabilidad del empleador por omisión del deber de control, a fin de relegar el elemento subjetivo del trabajador en la culpa grave, consistente en la inobservancia de las normas técnicas del uso de las maquinarias y asegurarle, por esta vía, la cobertura del seguro correspondiente ${ }^{36}$.

Distinto es el caso en el cual la víctima del accidente sea un trabajador que, por su posición al interno de la organización de la empresa, tenga entre sus funciones la responsabilidad de la seguridad de las maquinarias; en este supuesto se ha excluido la indemnización del accidente ocurrido por tal agravante (De Matteis, 2011: 197-198).

Otras legislaciones europeas han adoptado de manera análoga dichos supuestos, pero con efectos parcialmente distintos. Por ejemplo, en Suiza, el artículo 37 de la Legge federale sull'assicurazione contro gli infortuni $(\text { LAINF })^{37}$ hace distinciones diversas para cada supuesto; así, en el daño intencional excluye el derecho a las prestaciones del ente asegurador, en la negligencia grave reduce dichas prestaciones y en la negligencia simple no se produce incidencia alguna sobre las prestaciones.

En lo que concierne a la culpa del trabajador, esta se define a partir de la imprudencia, la negligencia, la impericia que entran en la noción misma del riesgo asegurado, exteriorizándose en un acto determinado lleno de circunstancias extrañas o ajenas a la ejecución de las prestaciones o al ambiente de trabajo otorgado al trabajador asegurado (Alibrandi, 2002: 326).

Asimismo, cuando hablamos de imprudencia, en relación con la culpa del trabajador, esta es a menudo el resultado de la poca familiaridad adquirida en el uso o manejo de instrumentos, a referidas situaciones de trabajo, a la negligencia y a la propia imprudencia, los cuales no varían la tutela del seguro obligatorio, en el sentido de excluirla o atenuarla. Así la culpa del trabajador, aunque sea causa exclusiva del accidente de trabajo, no debería exceptuar la aplicación de la indemnización correspondiente (De Matteis, 2011: 199).

El principio según el cual, la culpa del trabajador no resulta relevante para los fines de establecer la indemnización del accidente de trabajo, salvo algunas aisladas tentativas de

\footnotetext{
${ }^{35}$ La culpa grave, también conocida como culpa consciente o culpa con previsión, es la que se ocasiona cuando el accidente, si bien no es deseado, ha podido ser previsto por el accidentado. Al respecto, cfr. Fiandaca, Giovanni e Enzo Musco (2007). Diritto Penale-Parte general. Bologna: Zanichelli, p. 556 y ss; Riz, Roland (2000). Lineamenti di Diritto Penale-Parte general. Padova: CEDAM, pp. 271 y ss.; Romano, Mario (2004). Commentario sistematico del Codice Penale, I. Milano: Giuffre Editore, 441 y ss.

${ }^{36} \mathrm{Al}$ respecto, cfr. las sentencias de la Corte Suprema de la República Italiana, cfr. Casación de fecha 21 de enero de 1981, n. 505, en Giurisprudenza italiana, 1982, I, 1, 407; Casación de fecha 10 de diciembre de 1981, n. 6542; Casación de fecha 1 de octubre de 2003, n. 14645.

${ }^{37}$ Ley federal del seguro de los accidentes de trabajo de fecha 20 de marzo de 1981, publicado por disposición oficial del Gobierno suizo también como Bundesgesetz über die Unfallversicherung-UVG (en alemán) y Loi fédérale sur l'assurance-accidents- LAA (francés).
} 
disidencia, ha encontrado continuidad y consenso en la doctrina dominante; tanto es así que, en gran parte de Europa, ya desde la década de 1950, se podía afirmar la irrelevancia que tiene la culpa, en la determinación de la indemnización del accidente de trabajo, no es más materia de discusión. Una vez que el evento es objetivamente conectable a la actividad laboral desarrollada por el trabajador asegurado, no tiene ninguna importancia las modalidades de la conducta, se requiere simplemente que la víctima haya sufrido el accidente con ocasión del trabajo, y no en ocasión de un correcto, prudente o juicioso desempeño laboral, no se pretende que el trabajador, frente a la ejecución de las prestaciones, tenga la diligencia del buen padre de familia (Corsalini, 2009: 11-13).

Precisamente, la culpa del trabajador debe ser direccionada a la ocasión de trabajo, sin que esto derive en alguna reducción de la indemnización correspondiente, pero siempre a condición de que la imprudencia, negligencia o impericia sean redirigidos a un riesgo conexo con la actividad laboral (Ludovico, 2014: 144).

\section{Panorama sudamericano de la ocasión de trabajo}

La doctrina no ha dudado a la hora de afirmar que en la relación de trabajo los riegos a los que son expuestos los trabajadores son cada vez más intensos y frecuentes, por ello se impone la necesidad de desplegar una tutela de seguro contra accidente de trabajo más efectiva y específica, sometida a normas propias, mucho más incisiva y permanente, que se vincule en cada vez más al propio contrato de trabajo y al desarrollo de las prestaciones laborales que precise plenamente la función que desarrolla la ocasión como elemento esencial en la producción de los accidentes de trabajo porque son en la actualidad, más a menudo, los infortunios profesionales ligados al caso fortuito, la fuerza mayor o por factores conexos con la ejecución del trabajo. ${ }^{38}$.

Ya hace algún tiempo se acuñó la frase que el trabajo y el riesgo profesional están fatídicamente condenados a cohabitar en el desarrollo de la prestación laboral ${ }^{39}$, enunciado al que no debemos de extraer solo el lado negativo y fatalista de este tipo de riesgos sino, todo lo contrario, plantear la inexcusable necesidad de adoptar medidas específicas que busquen como finalidad la eliminación del riesgo profesional o al menos su disminución al menor rango posible y no se conforme con una mera protección frente al daño ya producido.

Como hemos mencionado, para que un accidente sea considerado de trabajo tiene que producirse en ocasión de tal actividad y así poder brindársele la tutela que a este evento le corresponda, ya sea a través de la indemnización correspondiente o de ser el caso, el resarcimiento del daño. La presencia de la ocasión como parte de la definición de accidente de trabajo está desarrollada, de manera específica, de alguna u otra forma, en diversas legislaciones nacionales, que en materia de protección contra accidente de trabajo existen en Sudamérica, pero aún se sigue optando por darle solo un enfoque causal o peor aún, a nivel doctrinal o jurisprudencial se trata a la ocasión como un sinónimo más de causa, lo que favorece a mantener la confusión.

\footnotetext{
${ }^{38} \mathrm{Al}$ respecto, Plá Rodríguez, Américo (1978). «Accidente de trabajo: ¿Seguro mercantil o Seguro Social?». Revista de Política Social, $\mathrm{N}^{\circ}$ 120. Madrid: Centro de Estudios Constitucionales: 7-27, señala que sólo una cuarta parte de los accidentes obedecen a la culpa del empleador, otra cuarta parte a la culpa del trabajador, y la restante mitad se origina por caso fortuito o fuerza mayor, o por factores desconocidos.

${ }^{39}$ Palomeque López, Manuel Carlos (1992). «El derecho constitucional del trabajador a la seguridad en el trabajo». En Actualidad laboral, $\mathrm{N}^{\circ}$ 1: 37-44.
} 
Este hecho, aunado a la visión de la protección contra el accidente de trabajo ligada más a la ambigua relación con los principios de la responsabilidad civil que aún, a través de sus tratadistas, no han podido unificar criterios respecto a las diversas opiniones dadas sobre la materia de la seguridad y la salud en el trabajo. Las razones de tal ambigüedad tienen un carácter histórico, cuando en un contexto fuertemente dominado por la lógica civilista, previo a la promulgación en Italia de la Ley $\mathrm{N}^{\circ} 80$ de 1898 que, como ya hemos señalado, instauró la obligatoriedad del seguro contra accidente de trabajo, y a falta de una enfoque teórico diverso y más apropiado, hizo que el único instrumento de protección social fuera, inevitablemente, el dirigido hacia la categoría dogmática de la responsabilidad civil, hecho que a pesar de los años y la evolución de los conceptos relacionados con la salud y seguridad del trabajo, continua aún vigente en mucho de nuestros países sudamericanos ${ }^{40}$.

Entre los países de América del Sur que han incluido dentro de sus legislaciones el término de ocasión de trabajo, de manera tácita o expresa, como un supuesto para la producción de un accidente laboral, para fines de este análisis, referimos los siguientes:

\section{Brasil}

Si bien el legislador brasileño hace una definición diversa a las contenidas en los otros ordenamientos jurídicos de Sudamérica, que en materia de accidentes de trabajo refieren a la ocasión de trabajo de manera expresa, desarrollando en el artículo 19 de la Ley $\mathrm{N}^{\circ}$ 8.213, de fecha 24 de julio de 1991, que dispuso los planes de los beneficios de la Seguridad Social, que, accidente del trabajo ${ }^{41}$ es el que ocurre por la ejecución del trabajo a servicio de la empresa o de empleador doméstico o por la ejecución del trabajo de los asegurados mencionados en el acápite VII, del artículo 11 de la referida ley, provocando lesión corporal o perturbación funcional que cause la muerte o la pérdida o la reducción, permanente o temporal, de la capacidad para el trabajo.

En primer término, se evidencia como diversa a las demás normativas de la región, porque basta continuar con la lectura de la norma para observar como legislativamente «equipara» a algunas enfermedades profesionales con los accidentes de trabajo; así se aprecia en los acápites I y II del artículo 20 de la referida ley que, considera también accidentes laborales a la enfermedad producida o desencadenada por la ejecución del trabajo perteneciente a una determinada actividad y que se encuentre en la respectiva relación elaborada por el Ministerio de Trabajo y de

\footnotetext{
${ }^{40} \mathrm{Al}$ respecto cfr. Ludovico, Giuseppe (2017). «Infortunio sul lavoro e malattie professionali: Tutela previdenziale e risarcimento del danno». En Gaetano Natullo y Paola Saracini (a cura di); Salute e sicurezza sul lavoro. Napoli: Editoriale Scientifica s.r.1.: 51-78.

${ }^{41}$ Es importante considerar la definición de la doctrina brasileña que define al accidente de trabajo como el evento dañoso relacionado directamente o no con el trabajo ejecutado, tratándose ya no de un infortunio en el trabajo sino de trabajo. Al respecto cfr. Balera, Wagner (2007). Curso de Direito Previdenciário. $3^{\circ}$ Ed. São Paulo: LTr: 109. Así también, a partir de una lógica más prevencionista, definen al accidente de trabajo como el comportamiento erróneo que el trabajador realiza en relación a la utilización de cualquier equipamiento, sin que se siga con el procedimiento correcto para su utilización, causándole daño en la salud, dejándolo imposibilitado de ejercer sus funciones con normalidad; así como también, a través de condiciones de inseguridad originados por equipamientos sin protección o el no suministro de los mismos, que pueden ocasionar el accidente; para un mayor análisis cfr. Ortiz, Edilson y Birolli, Silvio Luis (2009). O acidente do trabalho e as responsabilidades do empregador. En Revista interfaces: encino, pesquisa e extensão, 1 (1): 54.
} 
la Previsión Social; asimismo, a la adquirida o desencadenada en función de condiciones especiales en que el trabajo es realizado y que con él se relacione directamente, y que también se constate incluida dentro de la relación antes mencionada. Es importante citar que, dentro del mismo artículo, en el numeral 2, la norma prescribe también que otorga tutela, en «ciertos casos excepcionales», como si fuese accidente del trabajo, a enfermedad diversa que, aunque no esté determinada legalmente como accidente del trabajo, entiéndase, dentro de la relación descrita anteriormente, la Seguridad Social podrá considerarla como tal, en mérito a la atribución legal que la misma ley le confiere.

Así también, centrándonos propiamente en la ocasión de trabajo, la encontramos presente pero de manera tácita, desarrollada en diversos artículos de esta ley; así podemos apreciar supuestos que claramente se encontrarían relacionados dentro de sus alcances, porque de ningún modo entrarían en el contenido mismo de la definición general de accidente de trabajo que otorga el citado artículo 19, tales supuestos, entre otros son: el accidente relacionado con el trabajo que, aunque no haya sido la única causa, haya contribuido directamente a la muerte del asegurado, para reducir o perder su capacidad para el trabajo, o producir una lesión que exija atención médica para su recuperación; el accidente sufrido por el asegurado en el lugar y en el horario del trabajo, como consecuencia de un acto de agresión, sabotaje o terrorismo practicado por tercer o compañero de trabajo; una agresión física intencional, incluso de un tercero, por motivo de disputa relacionada al trabajo; un acto de imprudencia, de negligencia o de impericia de un compañero de trabajo o de un tercero; un acto de persona privada del uso de la razón; por el derrumbamiento, inundación, incendio y otros casos fortuitos o derivados de fuerza mayor; el accidente sufrido por el asegurado aunque este ocurra fuera del local y del horario de trabajo en la ejecución de orden o en la realización de un servicio bajo la autoridad de la empresa; en la prestación espontánea de cualquier servicio a la empresa para evitarle perjuicio o proporcionar provecho; en viaje al servicio de la empresa, incluso por estudio, cuando es financiado por ésta dentro de sus planes para mejorar la capacitación de la mano de obra, independientemente del medio de locomoción utilizado, inclusive vehículo de propiedad del asegurado; en el recorrido de la residencia al lugar de trabajo o de éste para aquella, cualquiera que sea el medio de locomoción, incluido el vehículo de propiedad del asegurado; en los períodos destinados a la comida o descanso; o con ocasión de la satisfacción de otras necesidades fisiológicas, en el lugar del trabajo o durante éste, el trabajador es considerado en el ejercicio del trabajo ${ }^{42}$.

Como se aprecia del párrafo anterior, los supuestos antes descritos no pueden ser entendidos como accidentes de trabajo sino fuese por el elemento ocasional allí presente, porque no se evidencia entre ellos una relación directa con la ejecución de la actividad laboral, sino una conexión tangencial, propia de la ocasión. Para la doctrina brasileña dichos supuestos los engloba dentro de la teoría de las concausas, definiendo para ello «concausa» como la otra causa que, junto a la principal, concurren para la producción del resultado. La concausa no inicia ni interrumpe el proceso causal, sólo lo refuerza, de la misma manera que un río afluente desemboca en uno principal, aumentando su caudal (Cavalieri Filho, 2015: 83).

Para el desarrollo de un accidente del trabajo, en sentido amplio, pueden contribuir causas ligadas a las actividades profesionales con otras extralaborales, sin ningún vínculo directo con la actividad laboral ejecutada por el trabajador; al mismo tiempo, incluso el accidente ya ocurrido

\footnotetext{
${ }^{42} \mathrm{El}$ integro de dicho supuestos "equiparables" al accidente de trabajo se encuentran descritos en el artículo 21 de la Ley $\mathrm{N}^{\circ} 8213$ de fecha 24 de julio de 1991.
} 
puede ser agravado por otra causa. Sin embargo, la aceptación normativa de la etiología multicausal no dispensa la existencia de una causa eficiente, derivada de la propia actividad laboral, que haya contribuido directamente con la producción del accidente del trabajo o con una situación equiparable, por lo que para determinar la concausa es indispensable la presencia de una causa de origen netamente laboral (Oliveira, 2017: 58).

Respecto al seguro contra accidentes del trabajo, este es obligatorio y es parte del régimen general de la seguridad social ${ }^{43}$, según establece el acápite II del artículo 22 la Ley $\mathrm{N}^{\circ} 8.212$, norma que dispuso la organización de la seguridad social, de fecha 24 de junio de 1991. Dicho seguro obligatorio es financiado mediante contribuciones pagadas exclusivamente por el empleador. Así, el porcentaje que cada empleador contribuye variará de acuerdo con el riesgo de las actividades desarrolladas por su empresa, cuanto mayor sea el riesgo, mayor será la contribución, esto porque actividades con un mayor riesgo potencial darán lugar a un mayor número de accidentes de trabajo, incluso con víctimas mortales $\mathrm{y}$, en consecuencia, aumentará el número de prestaciones por parte del ente asegurador, por lo que cada sector de actividad económica recibe una clasificación de riesgo, que equivale al 1\% para los riesgos leves, 2\% para los riesgos medios y $3 \%$ para los riesgos graves, de contribución sobre la base salarial, de acuerdo con el Código Nacional de la Actividad Económica - CNAE.

Asimismo, de acuerdo con la Ley $\mathrm{N}^{\mathrm{0}}$ 10.666, de fecha 8 de mayo de 2003, se estableció que puede haber un aumento del valor a ser pagado a favor del seguro obligatorio, al que denomina la legislación como Seguro de Accidente de Trabajo - SAT, en caso de que la empresa no atienda las expectativas de inversiones en prevención y control de accidentes de trabajo. Así, las alícuotas del Seguro de Accidente del Trabajo iniciales podrán ser aumentadas hasta un $100 \%$.

El denominado fator accidentário previdenciario ${ }^{44}$ oscilará de acuerdo con el historial de enfermedades y accidentes del trabajo por empresa, de forma que las alícuotas arriba mencionadas podrían alcanzar, respectivamente, el 2\%, el 4\% y el 6\% (Ortiz y Birolli, 2009: 57).

\footnotetext{
${ }^{43}$ En Brasil, hasta 1967, el Seguro de Accidentes del Trabajo estaba a cargo de la iniciativa privada, pero a partir del Decreto Ley $\mathrm{N}^{\circ} 293$, de fecha 23 de febrero de 1967, quedó establecido que el Estado, por medio del Instituto Nacional de Previsión Social - INPS, pasaría a operar el seguro contra los riesgos de los accidentes de trabajo en régimen de competencia con las sociedades de seguros (numeral 3 del artículo 1). Posteriormente, conforme a lo dispuesto en el artículo 1 de la Ley $\mathrm{N}^{\circ} 5316$, de fecha 14 de septiembre de 1967, el seguro obligatorio de accidentes del trabajo pasó a ser gestionado exclusivamente en la Seguridad Social, lo que ocurre hasta ahora; al respecto cfr. Melo, Raimundo Simão de (2013). Direito ambiental do trabalho e a saúde do trabalhador. $5^{\circ}$ Ed. São Paulo: LTr, pp 290-295.

${ }^{44}$ El fator acidentário de prevenção fue creado en base a los índices de gravedad y el costo de las ausencias de los trabajadores derivadas de la incapacidad para el trabajo de cada empresa, en comparación con los mismos índices de la respectiva actividad económica. Dependiendo del fator acidentário de prevenção determinado, el empleador pagará la contribución destinada a la financiación de la jubilación especial y de los beneficios concedidos debido al grado de incapacidad para el trabajo derivadas de los riesgos del ambiente laboral, conforme a lo previsto en el artículo 202 del Decreto №3048 de fecha 6 de mayo de 1999, con reducción del 50\% o ampliación hasta el 100\%; para un mayor análisis cfr. Oliveira, Sebastião Geraldo de (2017). Indenizações por acidente do trabalho ou doença ocupacional, $9^{\circ}$ Ed. São Paulo: LTr: 139-143.
} 


\section{Colombia}

El seguro en materia de accidentes de trabajo en Colombia ha transitado por varias etapas, las que podemos identificar genéricamente como: de responsabilidad del trabajador, de responsabilidad del empleador, de seguro público y de seguridad social (Cortés, 2009: 298).

En el año 2011 se produce una reforma estructural en la administración pública colombiana que involucró, entre otros, al sector de la protección social, a partir de las previsiones y facultades extraordinarias conferidas por la Ley $\mathrm{N}^{\circ} 1.444$ de fecha 4 de mayo de 2011 , de esta manera, se reorganizan los ámbitos del trabajo, la salud, la protección social, la inclusión social y la reconciliación. Los riesgos laborales quedan sometidos dentro de la política del Ministerio de Trabajo, sin perjuicio de la relación con los sectores de salud y protección social, particularmente en lo que se refiere a las prestaciones sociales.

Con la Ley $\mathrm{N}^{\circ} 1.562$, la cual modifica el Sistema de Riesgos Laborales y dicta disposiciones en materia de salud ocupacional, de fecha 11 de julio de 2012, se busca ampliar la cobertura de manera subjetiva, incluyendo de manera progresiva a los trabajadores independientes e informales (Ocampo y Osley, 2016: 184-203).

Si bien en el artículo $3^{\circ}$ de la ley citada en el párrafo anterior, define al accidente de trabajo como todo suceso repentino que sobrevenga por causa o con ocasión del trabajo ${ }^{45}$ y que produzca en el trabajador una lesión orgánica, una perturbación funcional o psiquiátrica, una invalidez o la muerte; también amplía dicha normativa la definición a aquel evento que se produce durante el ejercicio de las órdenes del empleador o el contratante durante la ejecución de una labor bajo su autoridad aún fuera del lugar y horas de trabajo.

Del mismo modo, la ley considera accidente de trabajo, al que se produce durante el traslado de los trabajadores o contratistas desde su residencia a los lugares de trabajo o viceversa, cuando el trasporte lo suministre el empleador. También se considerará como accidente de trabajo, el ocurrido durante el ejercicio de la función sindical, aunque el trabajador se encuentre con licencia sindical, siempre que el accidente se produzca en cumplimiento de dicha función. De igual manera, se considera accidente de trabajo, el producido por la ejecución de actividades recreativas, deportivas o culturales, cuando se actúe por cuenta o en representación del empleador o de la empresa usuaria, cuando se trate de trabadores de empresa de servicios temporales que se encuentre en misión.

Asimismo, la referida ley, en su artículo $2^{\circ}$, señala que la obligación de la afiliación al Sistema General de Riesgos Laborales ${ }^{46}$ para todos los trabajadores dependientes, los cuales asumirán el costo del referido seguro, mientras que en el caso de trabajadores que realizan labores catalogadas por el Ministerio de Trabajo colombiano como de alto riesgo, el pago será a

\footnotetext{
${ }^{45}$ Cuando la legislación colombiana hace referencia a la "ocasión de trabajo" hace referencia a la relación directa entre el oficio y el daño y por "causa del trabajo" quiere decir una relación mediata entre el oficio que se está desempeñando o el modo de hacerlo y el hecho dañoso; al respecto cfr. Rodríguez Mesa, Rafael (2015). Sistema de Riesgos Laborales. Barranquilla: Universidad del Norte Editorial, p. 49.

46 «Es el conjunto de entidades públicas y privadas, normas y procedimientos, destinados a prevenir, proteger y atender a los trabajadores de los efectos de las enfermedades y los accidentes que puedan ocurrirles con ocasión o como consecuencia del trabajo que desarrollan. Las disposiciones vigentes de salud ocupacional relacionadas con la prevención de los accidentes de trabajo y enfermedades laborales y el mejoramiento de las condiciones de trabajo hacen parte integrante del Sistema General de Riesgos Laborales». Al respecto, cfr. el artículo 1 de la Ley $\mathrm{N}^{\circ} 1562$ del 11 de julio de 2012.
} 
cuenta del empleador; asimismo, la afiliación a dicho seguro será voluntaria para el caso de los trabajadores independientes y los informales.

La jurisprudencia colombiana ${ }^{47}$, de manera uniforme, ha respaldado la teoría de la responsabilidad objetiva, hecho que emana de las disposiciones legales antes descritas, en contraste con una visión anterior del legislador colombiano que se proyectaba sobre la responsabilidad subjetiva del derecho común que imponía al afectado la carga de la prueba del elemento culpa; dichos antecedentes normativos supusieron para el trabajador la acreditación probatoria de la culpa del empleador y del daño ocasionado (lesión orgánica, perturbación funcional, invalidez, muerte), así como también la demostración de la relación causal entre uno y el otro. Era un periodo de influencia, en el cual el derecho laboral se encontraba regido por los principios del derecho común, que significó, como consecuencia, que el juzgador descartara la culpa del empleador cuando se encontrara en presencia de un accidente ocasionado por culpa del trabajador, culpa de un tercero o la fuerza mayor.

La aplicación de la teoría del riesgo profesional o responsabilidad objetiva en cierto sentido hizo a un lado la noción de culpa del empleador, es por ello que dejó de ser indispensable para comprometer o no la responsabilidad del mismo, de donde surgió, como lógica consecuencia de esa teoría, la obligación de reparar el daño ocasionado por el riesgo profesional, aunque mediara la culpa del trabajador (salvo el doloso o gravemente culposo), la culpa de un tercero o la fuerza mayor; así también, el legislador tarifó el resarcimiento del daño. Por eso ahora si el accidente ocurre por causa o con ocasión del trabajo, aunque ese acontecimiento corresponda a un imprevisto o suceso repentino, que no puede ser predecible por el empleador, aun así, queda comprometido en su responsabilidad frente al accidente de trabajo ${ }^{48}$.

Así, en los accidentes de trabajo, cuando los riesgos hayan podido prevenirse razonablemente por parte del empleador, con adecuadas medidas de seguridad, el valor de la indemnización se descontará de la condena ordinaria por perjuicios ${ }^{49}$ dictada por el juez. Cuando exista culpa suficientemente comprobada del empleador en la ocurrencia del accidente de trabajo

\footnotetext{
${ }^{47}$ Así, La Corte Suprema de Justicia, Sala de Casación Laboral, en la Sentencia N ${ }^{\circ} 23202$ del 29 de agosto de 2005 ha señalado que: «Partiendo de la base de que la causa en el accidente de trabajo comprende todas las circunstancias o eventos que, en cumplimiento o desarrollo de la actividad laboral, generan el acaecimiento del siniestro, debe concluirse que cuando se alude específicamente al accidente de trabajo in itinere, es exigencia para su estructuración, como requisito causal, objetivo y teleológico, el que el desplazamiento o traslado del trabajador para su ingreso o egreso del sitito de trabajo, deba estar motivado única y exclusivamente por el trabajo, estableciéndose de esa forma el nexo causal entre la lesión sufrida por el trabajador, en todos sus matices, y el trabajo que efectúa, conforme al lugar en que lo desarrolla y el itinerario que cumple para su ingreso o salida».

48 «El Tribunal analizó correctamente el hecho público y notorio consistente en el movimiento telúrico acaecido el día 25 de enero de 1999 en la ciudad de Armenia que le ocasionó la muerte violenta al señor Ocampo Rendón. Lo hizo, por cuanto, como se explicó al resolver el primer cargo, la fuerza mayor no rompe la pluralidad de causas, ni descarta el accidente de trabajo cuando se da el suceso durante la ejecución de órdenes del empleador o mientras adelanta una labor bajo su autoridad»; al respecto, cfr. Sentencia $N^{\circ} 17429$, de la Corte Suprema de Justicia, Sala de Casación Laboral, de fecha 19 de febrero de 2002.

${ }^{49}$ Así, el literal b) del artículo 8 del Decreto $\mathrm{N}^{\circ} 2350$ de 1944, prescribe: «Mientras se organiza el seguro social obligatorio, corresponderán también al patrono, además de las que le impongan leyes especiales o convenciones de trabajo, las siguientes indemnizaciones o prestaciones para con sus trabajadores, ya sean empleados u obreros... en el de accidentes de trabajo, cuando los riesgos hayan podido prevenirse razonablemente por parte del patrono, con adecuadas medidas de seguridad, el valor de la indemnización se descontará del monto de la condenación ordinaria por perjuicios».
} 
está obligado a la indemnización total y ordinaria por perjuicios, pero del monto de ella debe descontarse el valor de las prestaciones en dinero ya pagadas, en razón a las normas establecidas $^{50}$.

Asimismo, cuando el accidente de trabajo haya sido ocasionado por culpa imputable al empleador, se deberá proceder con el pago de la indemnización total y ordinaria por perjuicios. Si prospera esta indemnización, se descontará de su cuantía el valor de las prestaciones e indemnizaciones en dinero ya pagadas a mérito del citado accidente ${ }^{51}$. La entidad administradora de riesgo profesional podrá repetir, con sujeción a las normas pertinentes, contra tercero responsable de la contingencia profesional, hasta por el monto calculado de las prestaciones efectuadas a cargo de dicha entidad aseguradora, con sujeción en todo caso, al límite de la responsabilidad del tercero ${ }^{52}$.

Como se aprecia, en lo relativo a la culpa del empleador y conforme a la legislación colombiana vigente, detallada precedentemente, y en especial lo concerniente al Sistema General de Riesgos Laborales expuesto en la referida ley; seguirá a cargo del empleador la indemnización por accidente de trabajo cuando el acaecimiento de este sea por culpa imputable a él. La razón es que el ente asegurador de riesgos laborales no puede asumir la responsabilidad proveniente de la culpa del empleador, hecho que fue precisado también a nivel jurisprudencial ${ }^{53}$.

Si bien la responsabilidad civil del empleador no es asumida por el ente asegurador de riesgos laborales, como se ha dicho precedentemente, corresponde al empleador, de ser el caso, el pago del resarcimiento del daño ocasionado, quien podrá preverlo a través de otro seguro especializado en estas coberturas, que será un ente asegurador distinto al seguro de los riesgos profesionales, el cual es un seguro de responsabilidad contractual, por cuanto existe un contrato de trabajo o una relación laboral, pero el mejor seguro siempre será invertir en salud ocupacional (Ayala, 2005: 140).

\footnotetext{
${ }^{50}$ Es así como se señala en el Código Sustantivo del Trabajo, adaptado por el Decreto Ley N ${ }^{\circ} 2663$ publicado el 9 de septiembre de 1950, en su artículo 216: «Culpa Del Empleador. Cuando exista culpa suficiente comprobada del empleador en la ocurrencia del accidente de trabajo o de la enfermedad profesional, está obligado a la indemnización total y ordinaria por perjuicios pero del monto de ella debe descontarse el valor de las prestaciones en dinero pagadas en razón de las normas consagradas en este Capítulo».

${ }^{51}$ Expuesto así, en la parte final del numeral 2 del artículo 52 del Decreto $\mathrm{N}^{\circ} 1848$ de 1969: «Valor del seguro: ... a menos que el accidente de trabajo o la enfermedad profesional se hayan ocasionado por culpa imputable a la entidad o empresa empleadora, en cuyo caso habrá lugar a la indemnización total y ordinaria por perjuicios. Si prosperare esta indemnización, se descontará de su cuantía el valor de las prestaciones e indemnizaciones en dinero pagadas en razón de los expresados infortunios de trabajo».

${ }^{52}$ Extraído de lo expuesto en el artículo 12 del Decreto $\mathrm{N}^{\circ} 1771$ de 1994, que prescribe: «Subrogación. Compilado por el art. 2.2.4.4.7, Decreto Nacional 1072 de 2015. La entidad administradora de riesgos profesionales podrá repetir, con sujeción a las normas pertinentes, contra el tercero responsable de la contingencia profesional, hasta por el monto calculado de las prestaciones a cargo de dicha entidad administradora, con sujeción en todo caso al límite de responsabilidad del tercero.

Lo dispuesto en el inciso anterior no excluye que la víctima, o sus causahabientes, instauren las acciones pertinentes para obtener la indemnización total y ordinaria por perjuicio, de cuyo monto deberá descontarse el valor de las prestaciones asumidas por la entidad administradora de riesgos profesionales».

53 Al respecto, Corte Suprema de Justicia, Sala de Casación Laboral, en la Sentencia №5868 de fecha 12 de noviembre de 1993: «...para demandar el pago de la indemnización según el Código Sustantivo del Trabajo o según el derecho común, queda obligado a pagar el empleador cuando el accidente...se produce por acto intencional o culposo suyo...».
} 


\section{Chile}

Haciendo un breve repaso a la evolución histórica de las fuentes reguladoras del deber de seguridad en Chile, al inicio, dentro del régimen de responsabilidad por infracción a dicho deber, debemos señalar que este se encontraba marcado por la ausencia de un estatuto normativo especial, pues los daños derivados del accidente de trabajo eran resarcidos exclusivamente en base a las reglas del derecho común de la responsabilidad civil extracontractual; en tanto que los daños resarcibles de naturaleza extracontractual estaban restringidos, usualmente, al daño emergente y al lucro cesante. Fue a partir de la década de 1920 que la jurisprudencia chilena aceptó mayoritariamente el resarcimiento del daño moral ${ }^{54}$ en el ámbito aquiliano de la responsabilidad (Diez Schwerter, 2008: 254).

La normativa chilena actual, en el artículo $5^{\circ}$ de la Ley $\mathrm{N}^{\circ} 16.744$, establece las normas sobre accidentes del trabajo y enfermedades profesionales, publicada el 1 de febrero de 1968, señalando que: «Para los efectos de esta ley se entiende por accidente del trabajo toda lesión que una persona sufra a causa o con ocasión del trabajo, y que le produzca incapacidad o muerte»; además de ello otorga un cuerpo normativo en materia de seguridad laboral, estableciendo la obligatoriedad del Seguro Social contra Riesgos de Accidentes del Trabajo y Enfermedades Profesionales, delegando la administración del citado seguro a entidades de derecho público o privado, sin fines de lucro, como el Instituto de Seguridad Laboral (ISL), las Mutualidades de Empleadores y las Empresas con administración delegada ${ }^{55}$.

Un punto que cabe destacar dentro de la normativa chilena, es el alcance que da la ley respecto a la cobertura del seguro que, si bien es obligatorio, no tiene el Estado el monopolio. Son incluidos dentro de la cobertura del seguro los accidentes del trabajo conforme a la definición legal antes citada, también el accidente in itinere, los sufridos por dirigentes de instituciones sindicales a causa o con ocasión del desempeño de sus cometidos gremiales. Por su parte se excluyen los eventos debidos a fuerza mayor extraña que no tenga relación alguna con el trabajo y los producidos intencionalmente por la víctima ${ }^{56}$.

\footnotetext{
${ }^{54}$ El derecho inespecífico de la vida en integridad física y psíquica del trabajador, el cual sustenta el deber legal de seguridad contemplado en el artículo 184 del Código del Trabajo, al respecto cfr. Gamonal Contreras, Sergio (2007). El Daño moral en el contrato de trabajo. $2^{\mathrm{a}}$ ed. Santiago: Lexis Nexis, p. 18 y ss.

${ }^{55}$ Obligatoriedad

Artículo 1.- Declárase obligatorio el Seguro Social contra Riesgos de Accidentes del Trabajo y Enfermedades Profesionales, en la forma y condiciones establecidas en la presente ley.

Administración

Artículo 8.- La Administración del Seguro estará a cargo del Servicio de Seguro Social, del Servicio Nacional de Salud, de las Cajas de Previsión y de las Mutualidades de Empleadores, en conformidad a las reglas contenidas en los artículos siguientes.

${ }^{56}$ Artículo 5.- Para los efectos de esta ley se entiende por accidente del trabajo toda lesión que una persona sufra a causa o con ocasión del trabajo, y que le produzca incapacidad o muerte.

Son también accidentes del trabajo los ocurridos en el trayecto directo, de ida o regreso, entre la habitación y el lugar del trabajo, y aquéllos que ocurran en el trayecto directo entre dos lugares de trabajo, aunque correspondan a distintos empleadores. En este último caso, se considerará que el accidente dice relación con el trabajo al que se dirigía el trabajador al ocurrir el siniestro.

Se considerarán también accidentes del trabajo los sufridos por dirigentes de instituciones sindicales a causa o con ocasión del desempeño de sus cometidos gremiales.

Exceptúense los accidentes debidos a fuerza mayor extraña que no tenga relación alguna con el trabajo y los producidos intencionalmente por la víctima. La prueba de las excepciones corresponderá al organismo administrador.
} 
La jurisprudencia chilena ${ }^{57}$ que, sobre el fundamento de la obligación general de protección del empleador ${ }^{58}$, prescritos en el artículo 184 del Código de Trabajo, publicado el 16 de enero de $2003^{59}$ manifestó que, la sola ocurrencia de un accidente deviene en una presunción de culpa en contra del empleador que, por tratarse de una responsabilidad contractual, queda obligado a disponer todas las medidas de seguridad en favor del trabajador y a proporcionarle todos y cada uno de los elementos necesarios para prevenir cualquier tipo de accidente mientras ejecuta sus labores.

Asimismo, la jurisprudencia chilena ha configurado una especie de responsabilidad legal por incumplimiento, de tal forma que, cada vez que el empleador no pueda acreditar su diligencia, deberá responder frente a los accidentes producidos ${ }^{60}$. Conforme a este criterio, el deber empresarial se ha expuesto como un deber de resultado, manifestado en que, cada vez que se produzca un daño derivado de un accidente del trabajo, se colige que el deber de cuidado ha sido incumplido (Baraona, 2005: 132).

En ese escenario, las únicas circunstancias que conducirían a una excepción son, por un lado, el caso fortuito, es decir, un imprevisto no imputable al empleador y cuyas consecuencias no son posibles de evitar, en términos que ninguna persona en las mismas circunstancias habría podido preverlo ni impedirlo; y, por otro, la culpa exclusiva del trabajador (Sierra Herrero y Nasser Olea, 2012: 63-66).

\section{Perú}

En el caso del Perú, si bien en un primer momento, a inicios del siglo XIX, se adoptó la teoría del riesgo profesional, al presumirse la existencia de peligros inevitables en el trabajo,

${ }^{57}$ En materia de accidentes del trabajo, la responsabilidad del empleador, contemplada en los artículos 184 del Código del Trabajo y 69 de la Ley $\mathrm{N}^{\mathrm{0}} 16744$, surge con motivo del contrato de trabajo, esto es, tiene carácter contractual, circunstancia que lo obliga a disponer en favor del trabajador todas las medidas de seguridad y a proporcionarle todos los elementos necesarios para prevenir cualquier tipo de accidentes mientras ejecuta sus labores. De esta manera cabe concluir que, ocurrido el siniestro, corresponde al empleador probar que adoptó todas aquellas medidas y que proporcionó todos los elementos o implementos requeridos para evitar hechos como el ocurrido, otorgando la máxima seguridad posible en la faena, a su dependiente; al respecto cfr. Sentencia de la Corte Suprema de Justicia de Chile, recurso de casación de fecha 14 diciembre 2006. Rol 53-2005.

${ }^{58}$ La protección del trabajador gira en torno a un único elemento que no es otro que la obligación que pesa sobre el empresario de garantizar unas buenas condiciones de seguridad y salud en el trabajo. En la relación al trabajo vamos a encontrar, por tanto, una relación obligatoria básica en materia de seguridad y salud en el trabajo, donde el empresario ocupa la posición de deudor y el trabajador la de acreedor de seguridad. Al respecto cfr. Igartua Miró, María Teresa (2015). Sistema de prevención de riesgos laborales. $3^{\circ}$ Ed. Madrid: Editorial Tecnos: 133.

${ }^{59}$ Artículo 184.- El empleador estará obligado a tomar todas las medidas necesarias para proteger eficazmente la vida y salud de los trabajadores, informando de los posibles riesgos y manteniendo las condiciones adecuadas de higiene y seguridad en las faenas, como también los implementos necesarios para prevenir accidentes y enfermedades profesionales. Deberá asimismo prestar o garantizar los elementos necesarios para que los trabajadores en caso de accidente o emergencia puedan acceder a una oportuna y adecuada atención médica, hospitalaria y farmacéutica. Los organismos administradores del seguro de la ley $\mathrm{N}^{\circ} 16744$, deberán informar a sus empresas afiliadas sobre los riesgos asociados al uso de pesticidas, plaguicidas y, en general, de productos fitosanitarios.

${ }^{60}$ El deber de protección y seguridad impuesto al empleador en el artículo 184 del Código del Trabajo, tiene el carácter de obligación legal, de manera que debe ser el empleador quien deba acreditar que hizo efectivas todas las medidas de seguridad para eximirse de la responsabilidad que el legislador le atribuye. Al respecto confróntese las sentencias de la Corte Suprema de Justicia de Chile, recursos de casación de fecha 7 julio 2009. Rol 3143-2009 y de fecha 28 junio 2006. Rol 5381-2004. 
desvinculando las nociones de culpa y responsabilidad y, en su reemplazo, proponía considerar unitariamente los conceptos de daño y riesgo objetivo en la determinación de la carga probatoria e indemnizatoria. Las razones para recoger esta teoría a nivel legislativo, a través de la dación de la primera norma especializada en accidentes de trabajo, la Ley $\mathrm{N}^{\circ} 1.378$ de fecha 20 de enero de 2011, eran fundamentadas, principalmente en que todos los accidentes ocurridos en el trabajo debían ser reparados, al margen de la culpa del empresario o la imprudencia del trabajador, que tales accidentes eran considerados como riesgos inevitables del trabajo, debían valorarse al igual que las demás adversidades eventuales de la actividad laboral, que la atribución legal de la responsabilidad debía recaer en el titular de la empresa y que las indemnizaciones se deberían de deducir a partir de los ganancias de la producción. (Manzanilla, 1939: 57-65).

En la actualidad, el glosario expuesto en el Reglamento de la Ley $\mathrm{N}^{\circ}$ 29.783, Ley de Seguridad y Salud en el Trabajo, publicado el 25 de abril del 2012, define al accidente de trabajo como:

«Todo suceso repentino que sobrevenga por causa o con ocasión del trabajo y que produzca en el trabajador una lesión orgánica, una perturbación funcional, una invalidez o la muerte. Es también accidente de trabajo aquel que se produce durante la ejecución de órdenes del empleador, o durante la ejecución de una labor bajo su autoridad, aún fuera del lugar y horas de trabajo».

Como se aprecia, la normativa establece la definición de accidente de trabajo que también incluye la ocasión de trabajo, pero en la realidad la descripción legislativa dista mucho de la cobertura que dicho evento dañoso amerita.

La protección en salud tiene carácter constitucional, ${ }^{61}$ así como el derecho a la seguridad social $^{62}$, desarrollada más ampliamente en la Ley $\mathrm{N}^{\circ}$ 26.790, publicada el 17 de mayo de 1997. Ahora, por qué señalamos al sistema de seguridad social, porque es de manera general la única tutela que tiene actualmente un trabajador cualquiera, respecto a accidentes que pudieran sucederle, de índole laboral o no, ${ }^{63}$ y no solo ello, dicho seguro busca tutelar al mayor número de

\footnotetext{
${ }^{61}$ Constitución Política del Perú

Artículo 11.- El Estado garantiza el libre acceso a prestaciones de salud y a pensiones, a través de entidades públicas, privadas o mixtas. Supervisa asimismo su eficaz funcionamiento.

Artículo 10.- El Estado reconoce el derecho universal y progresivo de toda persona a la seguridad social, para su protección frente a las contingencias que precise la ley y para la elevación de su calidad de vida.

${ }^{62}$ Sin embargo, existe un evidente campo de interacción entre la Seguridad Social y el derecho de los trabajadores, entre ellos al seguro con los accidentes de trabajo, al respecto cfr. Neves Mujica, Javier (1987). La seguridad social en la constitución, en La constitución peruana de 1979 y sus problemas de aplicación (a cura de Francisco Eguiguren Praeli). Lima: Cultural Cusco Editores: 196.

${ }^{63}$ Ley de modernización de la seguridad social en salud, Ley N²6790, de fecha 15 de mayo de 1997.

Artículo 17.- Cobertura de los Trabajadores

La cobertura que ofrezca la Entidad Empleadora de conformidad con el Artículo. 15o., sea a través de servicios propios o de planes contratados, deberá contemplar los mismos beneficios para todos los trabajadores cubiertos y sus derechohabientes, independientemente de su nivel remunerativo... dicha cobertura deberá incluir la atención de accidentes de trabajo y enfermedades profesionales, cuando corresponda, y no podrá excluir la atención de dolencias preexistentes.
} 
ciudadanos posibles, ${ }^{64}$ en mérito del principio de universalidad de la seguridad social. ${ }^{65} \mathrm{El}$ problema es que resulta, en los hechos, ineficiente. ${ }^{66}$

Pero, qué hizo la referida ley, desarticuló lo que se había conseguido anteriormente con el Decreto Ley $\mathrm{N}^{\circ} 18.846^{67}$, que creó la Caja Nacional del Seguro Social Obrero, asumiendo exclusivamente la gestión del seguro por accidente de trabajo y enfermedades profesionales de los obreros, como un régimen especial financiado sólo por el empleador, el mismo que tenía que pagar aportaciones semanales a dicho ente asegurador. La responsabilidad obedecía a la teoría de la responsabilidad objetiva. El Seguro Social debía otorgar prestaciones médicas, aparatos de prótesis y ortopédicos, reeducación, rehabilitación y prestaciones en dinero; y siempre en la línea de definir al accidente laboral también como un evento ocurrido en ocasión del trabajo. ${ }^{68}$ No obstante, el reglamento de este Decreto Ley, aprobado por Decreto Supremo 002-TR del 24 de febrero de 1972, contempló, en su primera disposición general la posibilidad de que la víctima o sus herederos puedan instaurar las acciones pertinentes de derecho común para obtener la indemnización por perjuicios (Romero Montes, 2006: 8-9).

Retornando a la norma vigente, relativamente consciente el legislador del grado de indefensión en el que estaba dejando a la salud y la seguridad de los trabajadores crea, en la

${ }^{64}$ Reglamento de la ley de modernización de la seguridad social en salud, Decreto Supremo Nº09-97-SA, de fecha 8 de septiembre de 1997.

Artículo 7.- Son asegurados del Seguro Social de Salud los afiliados regulares y potestativos y sus derechohabientes. Son afiliados regulares: los trabajadores activos que laboran bajo relación de dependencia o en calidad de socios de cooperativas de trabajadores, y los pensionistas que reciben pensión de jubilación, incapacidad o sobrevivencia. Las personas que no reúnen los requisitos de afiliación regular, así como todos aquellos que la Ley determine, se afilian bajo la modalidad de asegurados potestativos.

${ }^{65}$ La Seguridad Social se rige por los principios de universalidad, integridad, solidaridad, unidad de sentido orgánico y estructural y la referida a la adecuación a un sistema unitario internacional, en ese sentido expuso la Sentencia del Tribunal Constitucional $\mathrm{N}^{\circ}$ 02835-2010-PA/TC del 13 de diciembre de 2011, para un mayor análisis cfr. Kresalja Roselló, Baldo y César Ochoa Cárdich (2009), Derecho Constitucional Económico. Lima: Fondo Editorial de la Pontificia Universidad Católica del Perú, p. 579.

${ }^{66}$ A pesar de la importancia de la sanidad pública, su gratuidad o bajo costo para el beneficiario, da lugar a una prestación mínima, insuficiente muchas veces para hacer frente a la necesidad, y crea un sentimiento de dependencia y humillación para quien acude a ella. Para los médicos, la sanidad pública es un medio para poner en práctica sus conocimientos o de ensayar las nuevas técnicas, que luego, ya comprobada su eficacia, aplican a sus pacientes particulares. Al respecto cfr. Rendón Vásquez, Jorge (1992). Derecho de la seguridad social. Lima: Tarpuy, p. 21.

${ }^{67}$ Decreto Ley N 18846 (derogado el 17 de mayo de 1997.)

Artículo 1. La Caja Nacional del Seguro Social Obrero asume exclusivamente el Seguro por accidente de trabajo y enfermedades profesionales del personal obrero en las condiciones fijadas por este Decreto Ley, encargándose, en consecuencia, de su gestión asistencial, administrativa, técnica y financiera.

Artículo 2.- Son asegurados obligatorios, a los efectos previstos por este Decreto Ley: a) Los trabajadores obreros de la actividad privada y de las empresas de propiedad social, los pescadores y los del servicio domésticos, cualquiera que sea la persona para la cual presten servicios; y b) Los trabajadores obreros del Sector Público, no comprendidos en el Decreto-Ley $\mathrm{N}^{\circ} 11377$.

Artículo 3.- Quedan comprendidos en este régimen todos los accidentes ocurridos en el trabajo o con ocasión directa del mismo. Este seguro cubre igualmente las enfermedades profesionales determinadas por el Reglamento correspondiente.

Artículo 4. Si los accidentes de trabajo a que se refiere el artículo anterior fuesen causados por un tercero, la Caja Nacional del Seguro Social Obrero tendrá derecho de exigir de éste, el

${ }^{68}$ Así lo define el artículo 3 del Decreto Ley 18846, publicado el 29 de abril de 1971 (hoy derogado): «Quedan comprendidos en este régimen todos los accidentes ocurridos en el trabajo o con ocasión directa del mismo. Este seguro cubre igualmente las enfermedades profesionales determinadas por el Reglamento correspondiente». 
misma norma, el Seguro Complementario de Riesgos ${ }^{69}$, un seguro contra accidentes de trabajo que otorga cobertura a los trabajadores, pero solo a determinados sectores de las actividades industriales, ${ }^{70}$ que asume el legislador son los de mayor riesgo. ${ }^{71}$ Seguro complementario (al sistema de seguridad social) que también define al accidente laboral como un evento ocurrido en ocasión de trabajo, pero, excluye de dicho concepto, contrariamente al estudio realizado en el presente artículo, a un grupo de infortunios, que por su relación con la ocasión estarían dentro de la definición doctrinal de accidente de trabajo, entre ellos el accidente in itinere, la culpa del trabajador, el caso fortuito, la fuerza mayor, etc. ${ }^{72}$

${ }^{69}$ Ley de modernización de la seguridad social en salud, Ley $\mathrm{N}^{\circ}$ 26.790, de fecha 15 de mayo de 1997. Artículo 19.- Seguro Complementario de Trabajo de Riesgo

El Seguro Complementario de Trabajo de Riesgo otorga cobertura adicional a los afiliados regulares del Seguro Social de Salud que desempeñan las actividades de alto riesgo determinadas mediante Decreto Supremo. Es obligatorio y por cuenta de la entidad empleadora. Cubre los riesgos siguientes: a) Otorgamiento de prestaciones de salud en caso de accidentes de trabajo o enfermedades profesionales, pudiendo contratarse libremente con el IPSS ó con la EPS elegida conforme al Artículo 15o. de esta Ley. b) Otorgamiento de pensiones de invalidez temporal o permanente y de sobrevivientes y gastos de sepelio, como consecuencia de accidentes de trabajo o enfermedades profesionales, pudiendo contratarse libremente con la ONP o con empresas de seguros debidamente acreditadas. El derecho a las pensiones de invalidez del seguro complementario de trabajo de riesgo se inicia una vez vencido el período máximo de subsidio por incapacidad temporal cubierto por el Seguro Social de Salud.

${ }^{70}$ Según el Anexo 5 del Reglamento de la Ley $N^{\circ}$ 26790: extracción de madera, pesca, explotación de minera, producción de petróleo crudo y gas natural, industria del tabaco, fabricación de textiles (excepto prendas de vestir), industria del cuero, industria maderera, fabricación de sustancias químicas industriales, refinería de petróleos, fabricación de productos derivados del petróleo y del carbón, fabricación de productos plásticos, fabricación de vidrios, industria básica de metales no ferrosos, fabricación de productos metálicos, construcción de maquinarias, electricidad, gas y vapor, construcción, transporte aéreo, servicio de saneamiento y similares, servicios médicos y sanidad veterinaria

${ }^{71}$ La doctrina peruana, bajo la denominación de riesgos laborales o profesionales, trata a los accidentes de trabajo y a las enfermedades profesionales, que tienen su causa, inmediata y directa, en el ejercicio de la actividad laboral dependientes. Se puede definir los riesgos profesionales desde el punto de vista de la salud como aquellas situaciones de trabajo que pueden romper el equilibrio físico, mental social de las personas. Al respecto cfr. Fajardo Crivillero, Martin (1992). Teoría general de la Seguridad Social. Lima: Ediciones Luis Alfredo, pp. 224-225; y Briceño, Rafael (2001). Seguridad y Salud en el Trabajo. Revista Análisis Laboral. Lima, XXV (286), pp. 29.

${ }^{72} \mathrm{Al}$ respecto confróntese el acápite 2.3 del artículo 2 de las normas técnicas del Seguro Complementario de Riesgo, aprobadas por Decreto Supremo N $^{\circ} 003-98-S A$, el 13 de abril de 1998, que señala:

«No constituye accidente de trabajo:

a) El que se produce en el trayecto de ida o retorno al centro de trabajo, aunque el transporte sea realizado por cuenta de la entidad empleadora, en vehículos propios contratados para tal efecto;

b) El provocado intencionalmente por el propio trabajador o por su participación en riñas o peleas u otra acción ilegal;

c) El que se produzca como consecuencia del incumplimiento del trabajador de una orden escrita específica impartida por el empleador;

d) El que se produzca con ocasión de actividades recreativas, deportivas o culturales, aunque se produzcan dentro de la jornada laboral o en el centro de trabajo;

e) El que sobrevenga durante los permisos, licencias, vacaciones o cualquier otra forma de suspensión del contrato de trabajo

f) Los que se produzcan como consecuencia del uso de sustancias alcohólicas o estupefacientes por parte del asegurado;

g) Los que se produzcan en caso de guerra civil o internacional, declarada o no, dentro o fuera del Perú; motín conmoción contra el orden público o terrorismo;

h) Los que se produzcan por efecto de terremoto, maremoto, erupción volcánica o cualquier otro tipo de convulsión de la naturaleza; 
En cuanto a la posibilidad del trabajador de demandar la responsabilidad civil por accidentes de trabajo, el Reglamento de la ley de modernización de la seguridad social en salud, Decreto Supremo No 009-97-SA, de fecha 8 de septiembre de $1997^{73}$ señala que, en los casos que una empresa que realiza actividades de riesgo, no contrate el referido seguro complementario para la totalidad de trabajadores o contrate coberturas insuficientes, asumirá el costo de las prestaciones brindadas al trabajador por el ente asegurador, independientemente de la responsabilidad civil frente al trabajador y sus beneficiarios, por los daños y perjuicios ocasionados.

Asimismo, tratándose de empleadores que no desarrollan actividades de riesgo, se establece que, si los mismos incumplen con abonar las cotizaciones del seguro social, que en este caso cubre los accidentes de trabajo, el ente asegurador otorgará las prestaciones y repetirá el pago contra el empleador, conforme lo prescribe la citada Ley $\mathrm{N}^{\circ} 26.790 .^{74}$

Actualmente, debe destacarse el cambio de enfoque regulador que existe en materia de seguridad y salud en el trabajo, aplicable de forma general para todos los trabajadores, la cual se encuentra recogida en la Ley $N^{\circ} 29.783$, Ley de Seguridad y Salud en el Trabajo, publicada el 20 de agosto de 2011, norma que como hemos expuesto anteriormente también considera a la ocasión como elemento participativo en el desarrollo del accidente de trabajo.

Además, uno de los principios ${ }^{75}$ que inspiran las disposiciones contenidas en la referida ley, es el de responsabilidad ${ }^{76}$, mediante el cual el empleador asume las implicancias económicas, legales y de cualquier otra índole, a consecuencia de un accidente o enfermedad que sufra el trabajador en el desempeño de sus funciones o a consecuencia de él, conforme a las normas vigentes; es por ello que, comprobado el daño sufrido por el trabajador y ante el incumplimiento del empleador del deber de prevención, se generará la obligación de pagar las indemnizaciones a

i) Los que se produzcan como consecuencia de fusión o fisión nuclear por efecto de la combustión de cualquier combustible nuclear, salvo cobertura especial expresa».

${ }^{73}$ Artículo 88: Sin perjuicio de las sanciones administrativas a que hubiere lugar, la Entidad Empleadora que no cumpla con inscribirse en el Registro referido en el artículo anterior o con la contratación del seguro complementario de trabajo de riesgo para la totalidad de los trabajadores a que está obligado o que contrate coberturas insuficientes será responsable frente al IPSS y la ONP por el costo de las prestaciones que dichas entidades otorgarán, en caso de siniestro al trabajador afectado; independientemente de su responsabilidad civil frente al trabajador y sus beneficiarios, por los daños y perjuicios irrogados.

${ }^{74}$ Artículo 10: Derecho a la cobertura

Cuando ocurra un siniestro por incumplimiento comprobado de las normas antes señaladas, el IPSS o la Entidad Prestadora de Salud que lo cubra, tendrá derecho a exigir de la entidad empleadora el reembolso del costo de las prestaciones brindadas.

${ }^{75}$ Otro de ellos es el principio de atención integral de salud, por el cual la referida ley señala que los trabajadores que sufran algún accidente de trabajo o enfermedad ocupacional tienen derecho a las prestaciones de salud necesarias y suficientes hasta su recuperación y rehabilitación, procurando su reinserción laboral. Lo anecdótico es que, a lo largo del contenido de la referida norma y su reglamento, no desarrolla como se materializará dicho principio.

${ }^{76}$ Ley de Seguridad y Salud en el Trabajo, Ley No29783:

Título Preliminar

II. Principio de Responsabilidad El empleador asume las implicancias económicas, legales y de cualquier otra índole a consecuencia de un accidente o enfermedad que sufra el trabajador en el desempeño de sus funciones o a consecuencia de él, conforme a las normas vigentes. 
las víctimas, o a sus herederos, de los accidentes de trabajo y de las enfermedades profesionales $^{77}$.

De modo complementario, el artículo $94^{\circ}$ del Reglamento de referida ley, aprobado por Decreto Supremo N ${ }^{\circ}$ 005-2012-TR, publicado el 25 de abril de 2012, precisa que, para afrontar la indemnización señalada en el párrafo anterior, debe existir una relación de causalidad entre el daño producido y el incumplimiento del empleador de las normas de seguridad y salud en el trabajo. Así, dicho precepto especifica lo siguiente:

«Para efecto de lo dispuesto en el artículo 53 de la Ley, la imputación de la responsabilidad al empleador por incumplimiento de su deber de prevención requiere que se acredite que la causa determinante del daño es consecuencia directa de la labor desempeñada por el trabajador y del incumplimiento por parte del empleador de las normas de seguridad y salud en el trabajo».

De los antes citados, se desprenden con claridad la posibilidad que el empleador asuma el pago de una indemnización por daños y perjuicios por la producción de accidentes de trabajo. En tal sentido, la norma sugiere que el Ministerio de Trabajo y Promoción del Empleo determine la indemnización cuando éste compruebe el daño acaecido; de lo cual se deduce que en los casos en que el ministerio no realice dicha comprobación (y determinación del pago de la indemnización), es posible que la indemnización por responsabilidad patronal se determine en la vía judicial, a través de una demanda de indemnización por daños y perjuicios, como en la actualidad viene sucediendo. ${ }^{78}$

${ }^{77}$ En el caso en que producto de la vía inspectiva se haya comprobado fehacientemente el daño al trabajador, el Ministerio de Trabajo y Promoción del Empleo determina el pago de la indemnización respectiva, en atención a ello el artículo 53 de la citada ley establece lo siguiente: "El incumplimiento del empleador del deber de prevención genera la obligación de pagar las indemnizaciones a las víctimas, o a sus derechohabientes, de los accidentes de trabajo y de las enfermedades profesionales. En el caso en que producto de la vía inspectiva se haya comprobado fehacientemente el daño al trabajador, el Ministerio de Trabajo y Promoción del Empleo determina el pago de la indemnización respectiva".

78 Así la jurisprudencia peruana viene aplicando criterios distintos respecto a la responsabilidad civil del empleador, la Corte Suprema de la República del Perú, durante el año 2016 tuvo enfoques distintos respecto a la responsabilidad civil frente a los accidentes de trabajo. Así, en la Casación Laboral N 4258-2016 ha establecido, en base al criterio de la responsabilidad contractual que: "Probada la existencia del daño sufrido por el trabajador, a consecuencia de un accidente de trabajo debe atribuirse el mismo al incumplimiento por el empleador de su deber de prevención, hecho que genera la obligación patronal de pagar a la víctima o sus derechohabientes una indemnización que será fijada por el juez conforme al artículo $1332^{\circ}$ del Código Civil, salvo que las partes hubieran aportado pruebas documentales o periciales sobre el valor del mismo".

De distinta manera se pronunció posteriormente, aplicando la teoría de la responsabilidad subjetiva, señaló en la Casación Laboral $N^{\circ} 18190-2016$, al establecer que: «Estando a lo expuesto, debemos señalar que con la documentación que corre en autos el actor ha probado que el daño sufrido fue ocasionado por un accidente de trabajo realizando sus funciones como Serenazgo; sin embargo, no se advierte documentación fehaciente que acredite que la demandada hubiera tenido alguna conducta antijurídica, toda vez que el accidente sufrido por el actor como consecuencia de la caída del asiento del copiloto cuando el vehículo se encontraba en marcha no implica que hubiera sido producto de una negligencia de la emplazada, más aún, si no se ha demostrado que el automóvil se encontraba en mal estado; además, se debe tener en cuenta que el accidente de trabajo aconteció en el año dos mil cuatro (2004) y la presentación de la demanda data del año dos mil doce (2012), transcurso del tiempo que impide a este Colegiado Supremo tener certeza de los hechos determinantes del accidente; en ese sentido, se puede concluir que pese a haberse acreditado el accidente de trabajo no se puede imputar a la demandada una conducta antijurídica cuando ésta 


\section{Uruguay}

Las enfermedades profesionales y los accidentes de trabajo pueden traer aparejado un estado de incapacidad física o invalidez de carácter permanente. Los programas que intentan cubrir estos riesgos, en casi todos los países del mundo entre los que se encuentra Uruguay, han incluido la invalidez sin discriminaciones, es decir, sin distinguir entre los accidentes de trabajo y las enfermedades profesionales. La primera norma en Uruguay que refiere a la reparación e indemnización de los riesgos profesionales es la Ley $\mathrm{N}^{\circ} 5.032$ de fecha 21 de julio de 1914, que establecía que el empresario tendría responsabilidad civil en caso de un accidente laboral si no cumplía con las normas que referían a la prevención de los infortunios en el trabajo; en este caso, eran los patronos los que se veían obligados a indemnizar a la víctima. La Ley $\mathrm{N}^{\circ} 9.743$ de fecha 26 de noviembre de 1920 y su modificatoria, la Ley $\mathrm{N}^{\circ} 10.004$ de fecha 28 de febrero de 1941, establecían las condiciones para ser beneficiario del seguro de accidentes del trabajo, este régimen era financiado por los patronos y el pago de la indemnización estaba a cargo del Banco de Seguros del Estado. ${ }^{79}$ El sistema, tal como lo determinaban las leyes anteriores, era obligatorio para todos los patrones que utilizaran el trabajo de obreros, incluido el Estado. El seguro sólo protegía el infortunio ocasionado a causa o en ocasión del trabajo (Sienra, 2007: 14-15).

En la actualidad, es clara la tendencia del legislador uruguayo, conforme a lo dispuesto en el artículo $2^{\circ}$ la Ley $\mathrm{N}^{\circ} 16.074^{80}$, publicada el 19 de enero de 1990, al señalar que la responsabilidad por los accidentes de trabajo recae en el empleador, quien es responsable de los accidentes de trabajo que sufran sus trabajadores a causa del trabajo o «en ocasión del mismo». Además, presenta la figura del seguro obligatorio. ${ }^{81} \mathrm{El}$ empleador tiene la obligación de contratar un seguro que cubre este riesgo, y debe hacerlo en el Banco de Seguros del Estado, que actúa en régimen de monopolio con relación a este tipo de seguros.

El empleador subroga su responsabilidad de indemnizar el accidente de trabajo en el Banco de Seguros del Estado mediante la contratación de dicho seguro; asimismo, existiendo el seguro obligatorio, el trabajador accidentado y si fuera el caso, sus herederos, deben dirigirse directamente ante este ente asegurador, quedando eximido el empleador de toda responsabilidad por este concepto y siéndole inaplicables por tanto las disposiciones del derecho común en este caso, conforme se refiere en el segundo párrafo del artículo 7 de la referida ley ${ }^{82}$.

no ha sido probada, es decir, el demandante no ha acreditado en autos la supuesta negligencia de la emplazada por el supuesto incumplimiento en realizar el mantenimiento correspondiente del vehículo, máxime, si el propio actor solo se limita a señalar que la culpa inexcusable de la demandada se debió porque le retiraron el apoyo para su rehabilitación, lo cual no es suficiente para imputar a la demandada la responsabilidad del daño sufrido».

${ }^{79}$ El Banco de Seguros del Estado tiene carácter monopólico desde 1914, respecto a estos seguros.

${ }^{80}$ Artículo $2^{\circ}$.- Todo patrono es responsable civilmente de los accidentes o enfermedades profesionales que ocurran a sus obreros y empleados a causa del trabajo o en ocasión del mismo, en la forma y condiciones que determinan los artículos siguientes.

${ }^{81}$ Artículo $1^{\circ}$.- Declárase obligatorio el seguro sobre accidentes del trabajo y enfermedades profesionales previsto en la presente ley.

${ }^{82}$ Artículo $7^{\circ}$.- Las personas amparadas por la presente ley, y en su caso, sus derecho-habientes, no tendrán más derechos como consecuencia de accidentes del trabajo y enfermedades profesionales, que los que la presente ley les acuerda, a no ser que en éstos haya mediado dolo por parte del patrono o culpa grave en el incumplimiento de normas sobre seguridad y prevención. En este caso además el Banco podrá aplicar las sanciones correspondientes (Pérdida del seguro, recuperaciones de gastos y multas). 
La responsabilidad del empleador frente a los accidentes de trabajo es amplia, dentro del sistema uruguayo, comprende también a los accidentes producidos mediante culpa del trabajador (leve o grave), o por caso fortuito o fuerza mayor; distinta a muchos otros ordenamientos en la región. ${ }^{83}$ Asimismo, el trabajador accidentado sólo pierde el derecho a la indemnización cuando provocó el accidente en forma dolosa ${ }^{84}$.

La indemnización del daño, esto es la indemnización tarifada a la que tienen derecho el trabajador accidentado es la establecida por la propia ley. La limitación de la responsabilidad del empleador a la indemnización tarifada se produce en el caso de que en el accidente haya mediado dolo del empleador o culpa grave en el incumplimiento de normas sobre seguridad y prevención.

Si se configuró dolo o culpa grave del empleador en el incumplimiento de norma de seguridad o prevención, el trabajador podrá reclamar directamente al empleador la reparación del daño o de la parte del daño no reparado por el Banco de Seguros del Estado, en base a las reglas de la responsabilidad civil. Además, el citado ente asegurador prestará asistencia médica y abonará las indemnizaciones que correspondieran a todos los trabajadores, con independencia de que sus empleadores hayan cumplido o no con la obligación de asegurarlos; sin perjuicio de las sanciones y recuperaciones a que hubiere lugar a ejecutar ${ }^{85}$.

La fórmula usada por el legislador uruguayo fue la de indicar que el trabajador no tendrá más derechos como consecuencia de accidentes del trabajo, que los que la referida ley les otorga a manera de indemnización, salvo que en estos accidentes haya mediado dolo por parte del

Acreditada por el patrono la existencia del seguro obligatorio establecido por la presente ley, la acción deberá dirigirse directamente contra el Banco de Seguros del Estado, quedando eximido el patrono asegurado de toda responsabilidad y siendo aplicables por tanto las disposiciones del derecho común. Todo ello sin perjuicio de la excepción establecida en el inciso anterior.

${ }^{83}$ Con arreglo a estos conceptos de la responsabilidad, el empleador uruguayo debía una indemnización en todos los casos, aun en aquellos en que el siniestro era imputable a la culpa leve o grave del obrero. Tal extensión de la responsabilidad patronal indujo a dar a esas indemnizaciones un carácter «forfaitaire»; pareció justo que la extensión dada a la responsabilidad del patrono tuviera una compensación en el calibraje económico de la indemnización. En realidad, él no era en general responsable de los accidentes cuyas consecuencias la ley lo obligaba a reparar; no debía pues una reparación integral. Al respecto, cfr. De Ferrari, Francisco (1971). Derecho del Trabajo. Vol. III, $2^{\mathrm{a}}$ ed. Buenos Aires: Editorial Depalma: 361- 362.

84 Artículo $9^{\circ}$.- Los siniestrados y en su caso los causahabientes, mantienen el derecho a la indemnización aun cuando el accidente se haya producido mediante culpa leve o grave de parte de aquéllos, o por caso fortuito o fuerza mayor, pero lo pierden en el caso de haberlo provocado dolosamente.

También pierde el siniestrado todo derecho a indemnización, cuando intencionalmente agrave las lesiones, o se niegue a asistirse o prolongue el período de su curación.

85 Artículo $8^{\circ}$.- El Banco de Seguros del Estado prestará asistencia médica y abonará las indemnizaciones que correspondieran a todos los obreros y empleados comprendidos por la presente ley, con independencia de que sus patronos hayan cumplido o no con la obligación de asegurarlos. Ello sin perjuicio de las sanciones y recuperos a que hubiere lugar.

Las indemnizaciones que abonará el Banco a siniestrados dependientes de patronos no asegurados se calcularán tomando como base un salario mínimo nacional.

A aquellos funcionarios públicos dependientes de Organismos que no estén al día en el pago de las primas o no hayan asegurado a sus funcionarios, sólo se les brindará asistencia médica.

El Banco de Seguros del Estado deberá exigir en todos los casos del patrono no asegurado, la constitución del capital necesario para el servicio de renta y el reembolso de los gastos correspondientes, conforme al procedimiento establecido en el artículo 36.

Constituido el capital correspondiente y pagados los demás gastos anexos por el patrono, o convenida con el Banco de Seguros del Estado una fórmula de pago, se efectuarán las reliquidaciones que correspondan. 
empleador o culpa grave en el incumplimiento de normas sobre seguridad y prevención. En estos casos, el Banco de Seguros del Estado podrá aplicar las sanciones correspondientes (pérdida del seguro, recuperaciones de gastos y multas); es decir que, en estos supuestos, el ente asegurador solicitará, por ejemplo, el rembolso de los gastos médicos y del capital para servir la renta en caso de que el accidente haya ocasionado una incapacidad permanente o la muerte del trabajador. Además, será el juez quien determinará en el caso concreto la configuración de la culpa grave del empleador en el incumplimiento de normas de seguridad y prevención; para ello analizará el conjunto de circunstancias de la situación en particular, a fin de establecer el monto correspondiente al resarcimiento del daño.

La ampliación de la responsabilidad del empleador (a través del resarcimiento del daño) en el fuero común, en los supuestos antes referidos, fue una modificación introducida en el sistema uruguayo por la citada ley, eliminando la injusticia del sistema anterior que equiparaba la situación del empleador cumplidor de las normas de seguridad con el patrono que no las respetaba (Mangarelli, 2014: 203-211).

\section{Conclusiones}

A lo largo del presente artículo hemos tratado de exponer cuales fueron los orígenes de la ocasión como requisito presente en el desarrollo del accidente de trabajo. Al respecto, es importante traer a colación, en este tramo final, que la evolución del concepto respondió principalmente, y como sucede en gran parte de las instituciones propias del Derecho al Trabajo, al enfoque (doctrinal, jurisdiccional y legislativo) que se dio directamente al contrastarse la teoría con la realidad y como esta se iba presentado. Así, en un inició se partió de los principios rectores de la responsabilidad civil, por lo que en el accidente de trabajo primó más que todo el criterio de causalidad, porque era lo que la doctrina civilista preponderante en ese momento impuso, hecho que a la postre fue superado.

La ocasión en el trabajo empieza a tener mayor protagonismo, no solo en Italia, sino en cualquier ordenamiento jurídico en el cual el seguro contra accidentes de trabajo evidenciaba una naturaleza obligatoria y social, esto es, que se busque como primer punto la necesidad de tutelar al trabajador, garantizando su condición no solo como tal, sino como ciudadano, ante la problemática generalizada del creciente número de accidentes de trabajo. Esto nos lleva a referirnos al término italiano «bisogno», que no encuentra un equivalente exacto en el español, porque no se refiere solo a una necesidad cualquiera, sino a la necesidad vital, esencial y primordial para seguir viviendo, es así que los sistemas de seguridad social buscan cautelar dichas necesidades, entre ellas la salud de los ciudadanos y evidentemente, inmersa en esta, la de los diversos trabajadores, en el entendido del papel que juega el trabajo en el progreso y desarrollo de las sociedades.

En este escenario, la participación del riesgo profesional es protagónico, porque permitió, en un primer momento, ampliar la visión de la tutela del seguro obligatorio en Italia, esta se expandió, ya no es más el criterio de causalidad el que predomina, sino el de la ocasión que va más ligado al aspecto teleológico que provoca el accidente, el trabajo es ese fin y no es más entendido como el causante de los accidentes, no es generador de ellos, pero sí de los peligros que a partir de él se originan, lo que la doctrina empieza a llamar riesgos profesionales, que pueden o no causar daño, justamente la condición para que el daño se produzca está en la 
ocasión, ese elemento que no está directamente relacionado con el trabajo pero que gira en torno a él y que al sumarse al riesgo profesional desencadenan el accidente de trabajo.

Como hemos mencionado, la necesidad de tutelar al trabajador contra los accidentes de trabajo tiene un trasfondo social, existe un interés colectivo que proteger, es así como, con el desarrollo de la industria, los riesgos profesionales como eran concebidos inicialmente se vinieron reduciendo, esto aunado al progreso de la tecnología y a un adecuado sistema de prevención contra este tipo de riesgos, colaboraron a que estos índices decrezcan. Pero la tutela estaba allí y el interés social de continuar otorgando esta cobertura permanecía latente, entonces cada vez menos eran los accidentes provocados por un riesgo directamente relacionado con el trabajo, empezaban a tener más incidencia aquellos riesgos genéricos, que podrían no solo afectar al trabajador, sino a cualquier otra persona pero que, a través de la ocasión del trabajo, fueron redirigidos a un escenario profesional; así empieza a darse cobertura a los accidentes ocurridos por caso fortuito, la fuerza mayor, la culpa del trabajador o de terceros; en consecuencia, es a través de la ocasión que se logra dar ese plus de finalidad laboral a estos eventos.

Ahora, en Sudamérica el enfoque es distinto, en muchos de nuestros ordenamientos se encuentra presente el término ocasión, pero solo es referencial, no tiene un rol preponderante, en algunos casos se aplica como sinónimo de causa. Asimismo, también están presentes los seguros contra accidentes de trabajo, de naturaleza obligatoria o complementaria a los sistemas de seguridad social, pero estas formas de tutela no evolucionaron y al no evolucionar, la ocasión de trabajo no pudo extenderse tampoco, entonces preexiste hasta ahora la tendencia a establecer los criterios de la responsabilidad civil, esto porque dichos seguros no otorgan una cobertura indemnizatoria adecuada, no son universales, carecen de automaticidad, presentan falencias estructurales considerables, que hacen que el trabajador accidentado tenga que recurrir a una vía alternativa, administrativa o judicial, para salvaguardar un interés propio, que debería ser entendido también por estos lares como un necesidad social para hacer frente a una problemática a la que no somos ajenos, porque la tutela contra accidentes de trabajo no es propio de determinados países, sino que tiene carácter global. Entonces, el trabajador accidentado, en muchos países sudamericanos, busca lograr obtener, a través de estas vías alterativas, una mejor cobertura indemnizatoria y de ser el caso, el resarcimiento del daño; esto conlleva a la aplicación de los criterios de la responsabilidad civil evidentemente, para establecer la culpabilidad de la producción del hecho antijurídico.

Este embrollo, respecto a la tutela contra los accidentes de trabajo, tiene un origen, es la poca inversión en tecnología, no solo en tecnología de seguridad y salud en el trabajo, sino en tecnología industrial en general, se prefiere en este lado del mundo, a nivel empresarial, continuar con los viejos sistemas de producción en desmedro de la salud del trabajador, esto porque la necesidad social de otorgarle una mayor protección, a nivel gubernamental no es aún materia de agenda política, no existe un interés real de los Estados de establecer acciones punitivas o incentivos (principalmente de índole económico, tributario o fiscal) para este tipo de actividades laborales generados del mayor índice de riesgos profesionales, para que de una vez se invierta en tecnología y seguridad. No es casualidad que en los países de economías más avanzadas, como en aquellos que en las últimas décadas han desarrollado exponencialmente sus economías, en la actualidad, sus índices de accidentes de trabajo se hayan reducido, esto porque han visto que la inclusión de la tecnología en las empresas, no solo trae mayor desarrollo económico sino, de manera directa, también los lleva a invertir en seguridad industrial, hechos que les genera, como 
consecuencia, ahorrar en los gastos que tendrían que hacer frente a la producción de continuos accidentes de trabajo.

\section{Referencias}

Agnelli, Arnaldo (1902). «V. Infortunio degli operai sul lavoro». Enciclopedia giuridica italiana, Vol. VIII, I: 995 y ss. Milano: Società Editrice Libraria.

Alibrandi, Giuseppe (1971). «I soggetti e l'oggeto del rapporto di assicurazione sociale». En Luisa Riva Sanseverino e Giuliano Manzoni (diretto da), Nuovo trattato di diritto del lavoro, Previdenza sociale. V. 3. Padova: CEDAM-Casa Editrice Dott. Antonio Milani.

Alibrandi, Giuseppe (2002). «Infortunio sul lavoro e malattie professionali». En Franceso Facello y Patrizio Rossi (a cura di), $11^{\circ}$ Ed.. Milano: Giuffrè Editore.

Alpa, Guido y Mario Bessone (2001). La responsabilità civile. Milano: Giuffrè Editore.

Antolisei, Francesco (1960). Manuale di diritto penale. Milano: Giuffrè Editore.

Ayala Cáceres, Carlos Luis (2005). Legislación en Salud Ocupacional y Riesgos Profesionales. $3^{\circ}$ Ed. Bogotá: Ediciones Salud Labora.

Baldi, Guido Maria (1930). «Cronache e storie della simulazione. Appunti e noterelle ai margini del processo di Roma». En Rassegna della previdenza social. X, 7.

Balera, Wagner (2007). Curso de Direito Previdenciário. $3^{\text {a }}$ edição. São Paulo: Editora LTr.

Baraona, Jorge (2005). «La culpa de la víctima en los accidentes del trabajo, dogmática y jurisprudencias chilenas». En AAVV, La responsabilidad por accidentes del trabajo (Jorge Baraona y Pedro Zelaya editores), Cuadernos de Extensión Jurídica-Universidad de los Andes, Santiago.

Barassi, Ludovico (1954). Previdenza Sociale e Lavoro Subordinato. Milano: Giuffrè Editore.

Briceño A., Rafael (2001). «Seguridad y Salud en el Trabajo». En Revista Análisis Laboral, XXV (286): 29-30. Lima.

Carnelutti, Francesco (1913). Infortuni sul lavoro, I. Roma: Athenaeum.

Cavalieri Filho, Sérgio (2015). Programa de responsabilidade civil. $12^{\circ}$ Ed. São Paulo: Atlas.

Corsalini, Guglielmo (2009). Gli infortuni in itinere. Estensione della tutela previdenziale $e$ risarcimento del daño. Milano: Wolters Kluwer Italia s.r.l.

Cortés Gonzáles, Juan Carlos (2009). Derecho de la protección social. Bogotá: Legis Editores S.A.

De Ferrari, Francisco (1971). Derecho del Trabajo. Vol. III. 2 ${ }^{\mathrm{a}}$ ed. Buenos Aires: Editorial Depalma.

De Matteis, Aldo (1996). L'assicurazione obbligatoria contro gli infortuni sul lavoro e le malattie professionali. Torino: Utet.

De Matteis, Aldo (2011). Infortuni sul lavoro e malattie professionali. Milano: Giuffrè Editore.

Diez Schwerter, José Luis (2008). «Responsabilidad civil derivada de accidentes de trabajo y enfermedades profesionales en Chile: evolución, funcionamiento y propuesta de racionalización». En Revista de Derecho Universidad de Concepción: 251-271.

Del Punta, Riccardo (2017). Diritto di Lavoro. $9^{\circ}$ Ed. Milano: Giuffrè Editore. 
Ewald, François (1987). Assurance Sociale, en L'etat providence. Livro III. Paris: Bernand Grasset.

Fajardo, Crivillero, Martin (1992). Teoría general de la Seguridad Social. Lima: Ediciones Luis Alfredo.

Ferrari, Genaro, Giulia Ferrari (2004). Infortunio sul lavoro e le malattie professionali. Padova: Cedam.

Fiandaca, Giovanni, Enzo Musco (2007). Diritto Penale-Parte general. Bologna: Zanichelli.

Fusinato, Guido (1887). Gli infortuni sul lavoro e il diritto civile, Scritti giuridici. Vol. II, 1921. Torino: Fratelli Bocca.

Gamonal Contreras, Sergio (2007). El Daño moral en el contrato de trabajo. $2^{\mathrm{a}}$ ed. Santiago: Lexis Nexis.

Giudici, Italo (1924). «Un caso di truffa in materia di assicurazione contro gli infortuni sul lavoro». En Rassegna della previdenza social. III. 25.

Hernández, Salvatore (1972). Lezioni di storia della previdenza sociale. Padova: CEDAM.

Igartua Miró, María Teresa (2015). Sistema de prevención de riesgos laborales. $3^{\circ}$ Ed. Madrid: Editorial Tecnos.

Kresalja Roselló, Baldo y César Ochoa Cárdich (2009). Derecho Constitucional Económico. Lima: Fondo Editorial de la Pontificia Universidad Católica del Perú.

Ludovico, Giuseppe (2012). Tutela previdenziale per gli infortuni sul lavoro e le malattie professionali e responsabilità civile del datore di lavoro. Milano: Giuffrè Editore.

Ludovico, Giuseppe (2014). «L’oggetto della tutela». En Stefano Giubboni, Giuseppe Ludovico y Andrea Rossi. Infortuni sul lavoro e malattie professionali. Padova: Cedam.

Ludovico, Giuseppe (2017). «Infortunio sul lavoro e malattie professionali: Tutela previdenziale e risarcimento del danno». En Gaetano Natullo y Paola Saracini (a cura di). Salute $e$ sicurezza sul lavoro. Napoli: Editoriale Scientifica s.r.1.: 51-78.

Ludovico, Giuseppe (2017). «Origen y evolución del seguro obligatorio de accidente de trabajo y enfermedades profesionales en Italia». En Revista chilena de derecho del trabajo y de la seguridad social, 8 (15): 13-36.

Mantovani, Ferrando (1992). Diritto penale. Padova: Cedam.

Manzanilla, José Matías (1939). La responsabilidad por los accidentes de trabajo. Discursos parlamentarios. $4^{\circ}$ ed. Lima: Librería e Imprenta Gil S.A.

Miraldi, Giovanni (1929). «Autolesionismo e simulazione nel campo degli infortuni sul lavoro: L'azione della Cassa nazionale infortuni». En Rassegna della previdenza social, I, 34.

Mori, A (1950). «Della evoluzione della legislazione di assicurazione contro gli infortuni sul lavoro». En Rivista degli infortuni e delle malattie professionali, I: 461 y ss.

Neve Mujica, Javier (1987). La seguridad social en la constitución, en La constitución peruana de 1979 y sus problemas de aplicación. (A cura de Francisco Eguiguren Praeli). Lima: Cultural Cusco Editores.

Nicolini, Giovanni (1966). «Rischio elettivo ed infortunio indennizzabile». En Rivista di diritto del lavoro.

Ocampo Olarte, Juan Guillermo y María Osley Garzón (2016). «El sistema de riesgos laborales frente al trabajador del sector informal». En Revista Opinión Jurídica. Universidad de Medellín, 15 (30): 183-203.

Oliveira, Sebastião Geraldo de (2017). Indenizações por acidente do trabalho ou doença ocupacional. $9^{\circ} \mathrm{Ed}$. São Paulo: LTr. 
Ortiz, Edilson y Silvio Luis Birolli (2009). «O acidente do trabalho e as responsabilidades do empregador». En Revista interfaces. Encino, pesquisa e extensão, 1 (1): 53-62.

Palomeque López, Manuel Carlos (1992). «El derecho constitucional del trabajador a la seguridad en el trabajo». En Actualidad laboral, 1: 37-44.

Pessi, Roberto (2006). Lezioni di diritto della previdenza sociale. Padova: Cedam.

Pezzoli, Liberato (1953). «Associazioni sindacali e prevenzione infortuni». En Rivista italiana di previdenza sociale.

Pic, Paul (1903). Traité élémentaire de législation industrielle: Les lois ouvrières. Paris: A Rousseau.

Plá Rodríguez, Américo (1978). «Accidente de trabajo: ¿Seguro mercantil o Seguro Social?». En Revista de Política Social, 120: 7-27. Madrid: Centro de Estudios Constitucionales.

Raimundo Simão De Melo (2013). Direito ambiental do trabalho e a saúde do trabalhador. $5^{\circ}$ Ed. São Paulo: LTr.

Ramírez Gronda, Juan (1938). Derecho del Trabajo. Buenos Aires: Editorial Claridad.

Rendón Vásquez, Jorge (1992). Derecho de la seguridad social. Lima: Tarpuy.

Riz, Roland (2000). Lineamenti di Diritto Penale-Parte general. Padova: CEDAM.

Rodríguez Mesa, Rafael (2015). Sistema de Riesgos Laborales. Barranquilla: Universidad del Norte Editorial.

Romano, Mario (2004). Commentario sistematico del Codice Penale, I. Milano: Giuffre Editore.

Romero Montes, Francisco (2006). La competencia y los riesgos laborales. En Cuadernos de Investigación y Jurisprudencia, 4 (10): 1-14. Lima: Centro de Investigaciones Judiciales.

Santoro-Passarelli, Francesco (1948). Rischio e bisogno nella previdenza sociale. In Rivista italiana di previdenza sociale, 177 y ss.

Schulz, Georg (1928). Abgrenzung zwischen Unfallversicherung und Krankenversicherung. Berlín.

Sierna, Mariana (2007). La evolución del sistema de seguridad social en el Uruguay (18291986). Instituto de Economía de la Facultad de Ciencias Económicas y de Administración. Montevideo: Universidad de la República.

Sierra Herrero, Alfredo y Marcelo Nasser Olea (2012). «Responsabilidad del empleador por enfermedades profesionales de sus trabajadores. Enfoque jurisprudencial». En Revista Chilena de Derecho, 39 (1): 57-76.

Vallebona, Antonio (2015). Breviario di Diritto del Lavoro. $9^{\circ}$ Ed., G. Torino: Giappichelli Editore. 